\title{
Em busca de incentivos para atrair o trabalhador autônomo para a Previdência Social
}

\author{
Marcelo Neri \\ Centro de Políticas Sociais/FGV e EPGE/FGV \\ Samantha Dart Tamm \\ Mestre pela EPGE/FGV \\ Flavio Menezes \\ EPGE/FGV \\ Leandro Kume \\ Doutorando pela EPGE/FGV
}

\begin{abstract}
Palauras-chave
previdência social, informalidade, conta-própria, mercado de trabalho.
\end{abstract}

Classificação JEL J26, H26, H55.

\section{Key words}

social security, informality, self-employed, labor market.

JEL Classification J26, H26, H55.

\section{Resumo}

Este artigo objetiva demonstrar que incentivos são capazes de influenciar a decisão do trabalhador autônomo de participar ou não do sistema público de Previdência (INSS) utilizando um arcabouço de Teoria de Contratos (modelo de Principal e Agente). A flexibilização das regras referentes à cessão de benefícios previdenciários para os mais pobres presentes na Constituição Federal de 1988 funciona como um laboratório sobre a reação da contribuição previdenciária a incentivos. A análise empírica, entretanto, contradiz as previsões do modelo teórico. Há um movimento generalizado de saída do sistema público de Previdência, mas esse movimento é mais acentuado exatamente no grupo dos autônomos mais ricos. Em termos teóricos, isso é explicado como uma violação das restrições de compatibilidade de incentivos. Em termos práticos, pode-se pensar esse movimento a partir da maior oferta de fundos de pensão privados existente no mercado, concorrendo com o INSS.

\section{Abstract}

This paper intends to show that economic incentives can affect the decisions of self-employed people whether to join or not the Brazilian social security system using a Principal-Agent framework. Relaxation of the rules for low income workers to access social security benefits promoted by the Federal Constitution of 1988 provides a laboratory to test such a model. The empirical analysis, however, contradicts the expectations of the theoretical model.

There is a general movement of withdrawal from the social security system yet this movement is more pronounced at the richest self-employed group. In theoretical terms, this is explained by a violation of the incentive compatibility constraints. One possible explanation is that the increase in the availability of private pension funds in the market has created competition for the government system. 


\section{1_Introdução}

O objetivo da Previdência Social é proteger o indivíduo contra situações adversas como morte, doenças, invalidez, desemprego, idade e velhice. Por meio de contribuições compulsórias, esse mecanismo reúne recursos a fim de oferecer uma série de benefícios, como seguro-desemprego, assistência à saúde, auxílio-maternidade, aposentadoria, entre outros. A Previdência Social funciona, dessa forma, como um sistema de seguro contra flutuações na renda de seus contribuintes.

Entre os diversos tipos de regime previdenciário existentes, dois merecem destaque: o sistema de capitalização e o sistema de repartição. No primeiro, a aposentadoria recebida pelo indivíduo provém de sua própria capitalização de recursos ao longo da vida ativa, e, no segundo, a aposentadoria é financiada pela contribuição dos indivíduos na ativa.

Embora o Brasil tenha adotado, inicialmente, um sistema previdenciário do tipo capitalização (Giambiagi e Além, 2000), posteriormente passou para um sistema de repartição graças à pressão do Estado por novos recursos. Como a estrutura etária da população era composta por uma parcela maior de indivíduos ativos em relação aos inativos, o sistema de repartição gerava superávits vultosos tornando mais atraente em termos financeiros.
Nos últimos anos, sistemas previdenciários do mundo inteiro vêm sendo tema de debate em razão dos crescentes déficits apresentados. $\mathrm{O}$ envelhecimento da população, por causa da queda nas taxas de natalidade e do aumento da expectativa de vida, é a principal causa apontada para a diferença entre benefícios aos inativos e contribuições dos ativos.

No Brasil, esse problema não é diferente. De acordo com o Instituto Brasileiro de Geografia e Estatística (IBGE), a média de filhos por mulher ao final da vida reprodutiva caiu de 6,2, na década de 1960 , para 2,3, em 1996. Por outro lado, a expectativa de vida subiu de 42 anos na década de 1940 para 68 anos em 1996. Além disso, estima-se que a expectativa de vida, em 2020, atinja 76 anos. A participação da população idosa (acima de 65 anos) na população total subiu de 4\%, em 1980, para $5,4 \%$, em 1996, com previsões de $11 \%$ para 2020 .

Contudo, o novo padrão demográfico brasileiro não é o único responsável pela reversão dos superávits do regime previdenciário nos últimos anos. A Constituição Federal, promulgada em 1988, criou uma série de benefícios sem alterar os mecanismos de financiamento, agravando o desequilíbrio atuarial do sistema previdenciário brasileiro. Algumas das principais mudanças foram a definição do piso de um 
salário mínimo para todos os beneficiários, eliminando as diferenças entre os pisos rural e urbano, e a redução de 5 anos na idade mínima necessária para aposentadoria por velhice dos trabalhadores rurais. Como conseqüência, a despesa com os benefícios rurais em manutenção duplicou além do aumento instantâneo do número de trabalhadores elegiveis para a aposentadoria.

Além disso, a nova Constituição alterou os incentivos na decisão em participar da Previdência ao ampliar os benefícios para indivíduos de fora do regime. O sistema de saúde público e a aposentadoria, por exemplo, que antes eram um direito dos contribuintes do regime previdenciário, passaram a servir a toda população. Embora, no Brasil, a participação no sistema previdenciário seja obrigatória, é de senso comum que muitos indivíduos optam por burlar essa regra, incentivados pela ineficiência da Justiça e pela falta de uma fiscalização mais rigorosa por parte do Estado. Mesmo aqueles que contribuem para esse sistema, muitas vezes pagam um valor menor do que deveriam ao informar uma renda menor do que o condizente (Oliveira e Beltrão, 1999).

Outro fator igualmente importante que afeta a arrecadação líquida do sistema previdenciário é o problema de informa- ção assimétrica gerado pelo desconhecimento do governo em relação à renda de cada cidadão. Como forma de maximizar sua receita e diminuir a desigualdade de renda do País, o governo, ao invés de elaborar contratos para cada tipo de indivíduo, é obrigado a oferecer planos de previdência genéricos, constando benefícios e contribuições, de modo que os próprios indivíduos, ao escolherem os contratos que melhor lhes agradem, diferenciem-se em relação à renda revelando seu tipo. Esse processo, contudo, é custoso.

Grande parte dos artigos já publicados no Brasil sobre este assunto concentra-se em estudar a sustentabilidade do sistema previdenciário ou a viabilidade de se fazer uma transição de sistemas de repartição para sistemas de capitalização, utilizando modelos de gerações superpostas, equilibrio parcial e geral. Entre os principais trabalhos nessa área, destacam-se Kandir (1994), Gramlich (1996), Oliveira e Beltrão (1996), Rondanelli (1996), Giambiagi e Além (1997), Giambiagi (2002). Essas propostas apresentadas, embora sejam factíveis e estejam sendo colocadas em prática em diversos países, encontram relutância, uma vez que afetam benefícios conquistados, ao longo de vários anos, da previdência social de grande parte da população. 
Nenhum desses trabalhos, no entanto, analisa o efeito do problema de informação assimétrica sobre a arrecadação líquida da Previdência, nem o efeito da Constituição de 1988 sobre os incentivos dos indivíduos em participar do regime previdenciário. $\mathrm{O}$ estudo desses problemas permite entender outros fatores que contribuem para a deterioração na conta $\mathrm{da}$ Previdência, além de sugerir novas opções para adequá-las.

Este trabalho tem dois objetivos. Primeiro modelar, com base em um arcabouço de desenho de mecanismos, o efeito da Constituição de 1988 sobre os incentivos dos indivíduos em participar do sistema previdenciário. Embora a renda de cada potencial contribuinte, teoricamente, seja de conhecimento do governo, na prática isso não ocorre, visto que a maioria dos indivíduos recebe, informalmente, de alguma forma, uma renda extra que pode em alguns casos, corresponder à totalidade da renda obtida. Além disso, mediante um modelo simples de informação perfeita, é possível verificar que existe um ganho financeiro em melhorar a fiscalização sobre a renda informada pelos contribuintes da Previdência. Por fim, utilizando dados da Pesquisa Nacional por Amostragem de Domicílios (PNAD), algumas estimações são feitas de modo a se comparar os resultados obtidos do modelo teórico.
De modo geral, este trabalho revela alguns mecanismos por meio dos quais políticas voltadas para uma maior fiscalização na declaração das contribuições previdenciárias podem resultar em uma maior arrecadação. Além disso, testamos alguns efeitos da Constituição de 1988. A introdução da nova Carta Magna diminuiu os incentivos dos trabalhadores em participar do sistema previdenciário sobretudo no caso dos trabalhadores autônomos de baixa renda. Contudo, essa hipótese foi rejeitada pela evidência empírica apresentada.

O trabalho é dividido em quatro partes além desta introdução. Na primeira, descrevemos a situação atual do sistema previdenciário brasileiro. $\mathrm{Na}$ segunda, apresentamos um modelo teórico com variantes de hipóteses de acesso a informação no qual demonstramos que é possível aumentar a arrecadação previdenciária com adoção de maior fiscalização no pagamento da Previdência, de forma que os contribuintes não omitam sua renda verdadeira. Além disso, são feitas algumas modificações no modelo para mostrar como a Constituição de 1988 alterou os incentivos dos indivíduos em participar da Previdência. A seguir, são realizados alguns testes empíricos, e seus resultados são comparados com o modelo teórico. Por fim, comentam-se as conclusões. 
1 O déficit da Previdência é aqui definido como o total de benefícios pagos menos a arrecadação líquida do INSS, que leva em conta os descontos do Sistema S (Sesc, Sesi, Senae e Sebrae).

2 Existe a possibilidade de o sistema estar no lado errado da Curva de Lafer, ou seja, quanto mais se aumentam as alíquotas, menor o volume de contribuições. Para mais referências, ver World Bank (2000) e Neri (2003).

\section{2_Evidências do sistema de Previdência brasileiro}

O superávit previdenciário que correspondia a $\mathrm{R} \$ 12,9$ bilhões em 1988 se transformou em déficit de $\mathrm{R} \$$ 6,7 bilhões em 1998. Embora a arrecadação líquida da Previdência tenha se elevado substancialmente, nesse período, o pagamento de benefícios aumentou numa proporção ainda maior, como pode ser visto na Tabela $1 .^{1}$ A previsão para os próximos anos é de piora nesse resultado.

Além disso, deve-se lembrar que, nos últimos anos, houve significativa alteração no perfil do mercado de trabalho. Enquanto a maior parte da arrecadação da Previdência é fruto da contribuição sobre salários do mercado de trabalho formal, a parcela dos trabalhadores com carteira assinada nas regiões metropolitanas é cada vez menor. Paralelamente, o número de autônomos (conta-própria) e de sem carteira tem crescido continuamente (Tabela 2). As altas alíquotas de contribuição social são, em parte, responsáveis por esse processo, que resulta na queda de arrecadação do governo e, conseqüentemente, em novos aumentos de alíquotas, fechando o círculo vicioso. ${ }^{2}$

Dada essa situação em que se encontra o sistema previdenciário brasileiro, seria de se esperar que o governo concentrasse seus esforços em duas frentes. A primeira, e mais óbvia, seria atrelar a contribuição ao benefício. Durante muitos anos o valor a ser recebido era calculado com base nos últimos 36 meses de contribuição, o que causava forte distorção. A introdução do fator previdenciário (Lei n. 1.527, de 1999) começou a corrigir isso, atrelando os benefícios a todo o período de contribuição do segurado e incentivando a permanência na ativa dos trabalhadores. Seu impacto sobre as escolhas dos autônomos, contudo, deve ser percebido aos poucos, dando-se tempo para que todos os trabalhadores incorporem as novas informações em seu processo de tomada de decisão.

A segunda frente seria atrair para o sistema a economia informal. Como já disse o então ministro da Previdência Waldeck Ornélas, em artigo publicado na revista Conjuntura Econômica (novembro de 1999), existe uma necessidade de estimular a filiação dos trabalhadores autônomos, estimados em cerca de $30 \mathrm{mi}$ lhões. O volume de receita em potencial proveniente de trabalhadores sem carteira e dos conta-própria não pode ser ignorado (Tabela 3). 
Tabela 1_Evolução do Déficit da Previdência - RGPS (em R\$ bilhões - preços constantes dez./98)

\begin{tabular}{|c|c|c|c|}
\hline & Arrecadação líquida & $\begin{array}{c}\text { Pagamento } \\
\text { de benefícios }\end{array}$ & Saldo previdenciário \\
\hline 1988 & 30,79 & 17,83 & 12,959 \\
\hline 1989 & 30,49 & 19,04 & 11,450 \\
\hline 1990 & 31,50 & 19,52 & 11,981 \\
\hline 1991 & 28,32 & 20,47 & 7,850 \\
\hline 1992 & 27,93 & 22,28 & 5,657 \\
\hline 1993 & 31,74 & 29,97 & 1,772 \\
\hline 1994 & 32,88 & 33,07 & 0,809 \\
\hline 1995 & 40,69 & 41,02 & $-0,325$ \\
\hline 1996 & 44,36 & 44,48 & $-0,124$ \\
\hline 1997 & 45,89 & 49,06 & $-3,177$ \\
\hline 1998 & 46,74 & 53,49 & $-6,752$ \\
\hline
\end{tabular}

Fonte: MPAS/SPS.

Tabela 2_ Distribuição da população brasileira ocupada de 15 anos e mais, por posição na ocupação (em porcentagem)

\begin{tabular}{|c|c|c|c|c|c|}
\hline Período & $\begin{array}{c}\text { Empregados } \\
\text { com carteira } \\
\text { assinada }\end{array}$ & $\begin{array}{c}\text { Empregados } \\
\text { sem carteira } \\
\text { assinada }\end{array}$ & Conta-própria & Empregador & Total \\
\hline 1991 & 54,76 & 20,78 & 20,01 & 4,43 & 100 \\
\hline 1992 & 52,42 & 22,21 & 21,00 & 4,39 & 100 \\
\hline 1993 & 51,53 & 23,09 & 21,11 & 4,34 & 100 \\
\hline 1994 & 49,25 & 24,70 & 21,80 & 4,23 & 100 \\
\hline 1995 & 48,40 & 24,10 & 22,03 & 4,49 & 100 \\
\hline 1996 & 46,69 & 24,78 & 22,83 & 4,61 & 100 \\
\hline 1997 & 46,37 & 24,80 & 23,33 & 4,52 & 100 \\
\hline 1998 & 45,85 & 25,40 & 23,22 & 4,54 & 100 \\
\hline
\end{tabular}

Fonte: IBGE. Pesquisa Mensal de Emprego.

Nota: A soma das parcelas para 1995 e 1998 não atinge 100\% em função de arredondamentos. 
Tabela 3_Contribuinte do INSS e pessoas ocupadas conforme categorias ocupacionais declaradas à PNAD 1997

\begin{tabular}{|c|c|c|c|}
\hline Categorias & INSS & PNPD & $\%$ \\
\hline Domésticos & 1.080 .306 & 5.242 .846 & 20,61 \\
\hline Autônomos (contra-própria) & 2.092 .011 & 15.740 .607 & 13,29 \\
\hline Empregados & 1.254 .395 & 2.794 .804 & 44,88 \\
\hline Total & 4.426 .712 & 23.778 .257 & 18,62 \\
\hline
\end{tabular}

Fonte: IBGE (Pesquisa Nacional de Amostra por Domicílios, 1997); MPAS.

\section{3_ O modelo}

Esta seção está subdividida em três partes. Na primeira, um modelo de informação perfeita é apresentado com o objetivo de se comparar seus resultados com o modelo de informação assimétrica desenvolvido na subseção seguinte. Por fim, algumas modificações no modelo de informação assimétrica são introduzidas, a fim de captar o efeito da Constituição de 1988 sobre a decisão dos indivíduos em participar do sistema previdenciário.

Nos três modelos desenvolvidos a seguir, supõe-se que os indivíduos sejam homogêneos exceto na renda, isto é, têm a mesma idade, esperança de vida, riscos de invalidez e desemprego. Existem dois tipos de indivíduo (Agente), um com renda alta, $\theta_{H}$, e outro com renda baixa, $\theta_{L}$ e suas respectivas distribuições são $\lambda$ e $1-\lambda$, sendo que $0 \leq \lambda \leq 1$. O governo (Principal), em um dado momento, oferece contratos de previdencia, e os indivíduos decidem qual deles aceitar ou se não participam desse sistema. Passado esse instante, não é possível mais entrar ou sair do regime de Previdência. Essas hipóteses, embora simplifiquem bastante o modelo tornando estática a escolha dos indivíduos, são importantes para explicar como o diferencial de renda afeta a arrecadação previdenciária para os indivíduos que estão ingressando no mercado de trabalho pela primeira vez. ${ }^{3}$

O objetivo do governo é maximizar o valor presente de sua receita líquida oferecendo contratos $\left(p_{i}, B_{i}\right)$, onde $p_{i}$ e $B$ são, respectivamente, o valor presente das contribuições e dos benefícios do sistema previdenciário para um indivíduo tipo i. É fácil notar que o governo ofertará dois tipos de contrato, um para cada tipo de indivíduo. Esses contratos estão sujeitos a duas restrições:

a. o contrato deve ser vantajoso para o indivíduo aceitá-lo (restrição de participação); 
b. o contrato deve revelar seu tipo corretamente (restrição de compatibilidade de incentivos).

A seguir, algumas hipóteses são feitas com relação à receita do governo $(R)$ e a função utilidade dos indivíduos.

\section{a. $p \in[0, \bar{p}]$}

O pagamento do indivíduo tem que ser maior ou igual a zero e tem um limite superior, $\bar{p}{ }^{4}$

$$
\begin{aligned}
& \text { b. } R=R(p), R(0)=0, R^{\prime}(p)>0 \\
& \quad \text { e } R^{\prime \prime}(p)=0
\end{aligned}
$$

A receita do governo é uma função linear dos pagamentos realizados pelo indivíduo e, se esse pagamento for zero, a receita será igual a zero.

$$
\begin{gathered}
\text { c. } u(B, p, \theta)=v(B-g(p, \theta), \\
\text { onde } v^{\prime \prime}(.)<0
\end{gathered}
$$

$\mathrm{O}$ indivíduo é avesso ao risco, e sua utilidade depende do valor presente dos benefícios, $B$, das contribuições à Previdência, $p$, e do seu tipo, $\theta$. A função $g(p, \theta)$ representa o valor das contribuições previdenciárias, dado seu tipo, em relação aos benefícios recebidos.

$$
\text { d. } g(0, \theta)=0 \forall \theta
$$

Se o indivíduo não pagar nada, sua desutilidade é igual a zero, independentemente do seu tipo.

$$
\begin{aligned}
& \text { e. } \frac{\partial g(p, \theta)}{\partial p}>0 \text { se } p>0 \\
& \frac{\partial g(p, \theta)}{\partial p}=0 \text { se } p=0
\end{aligned}
$$

Quanto maior o pagamento, maior a desutilidade do indivíduo.

$$
\text { f. } \frac{\partial^{2} g(p, \theta)}{\partial p^{2}}>0 \forall p
$$

Quanto maior o pagamento, maior a desutilidade marginal do indivíduo.

$$
\text { g. } \frac{\partial g(p, \theta)}{\partial \theta}<0 \forall p
$$

Quanto maior o $\theta$, mais alta é a renda do indivíduo e, portanto, menor sua desutilidade de contribuir para a Previdência. Esta hipótese tem suporte na evidência empírica, já que indivíduos com renda mais alta estão menos propensos a omitir sua verdadeira renda, dado que no Brasil é obrigatória a contribuição previdenciária.

$$
\begin{aligned}
& \text { h. } \frac{\partial^{2} g(p, \theta)}{\partial \theta \partial p}<0 \text { se } p>0 \\
& \frac{\partial^{2} g(p, \theta)}{\partial \theta \partial p}=0 \text { se } p=0
\end{aligned}
$$

Quanto maior o $\theta$, mais alta é a renda do indivíduo e, portanto, menor sua desutilidade marginal de contribuir para a Previdência.
4 "Na verdade, a contribuição do indivíduo, p, é uma variável discreta. Aqui está sendo colocada como variável contínua, a fim de simplificar a análise, uma vez que os resultados não devem se alterar significativamente. 
i. As utilidades de reserva dos indivíduos de alta e baixa renda são, respectivamente, $u_{H}$ e $u_{L}$, onde $u_{H}>u_{L}$. Como grande parte dos benefícios do sistema pre- videnciário, como o benefício assistencial de um salário mínimo, privilegia a parcela da população mais pobre, é de se esperar que seu custo de oportunidade seja menor. ${ }^{5}$

\section{1_Quando $\theta$ é observável}

Quando o governo observa a renda dos indivíduos, seu problema fica especificado da seguinte forma:

$$
\begin{aligned}
& \operatorname{Max}\left[\mathrm{R}\left(p_{i}\right)-B_{i}\right] \\
& B_{i}, P_{i} \geq 0 \\
& \text { s.a } v\left[B_{i}-g\left(p_{i}, \theta_{i}\right)\right] \geq u_{i}
\end{aligned}
$$

Na solução ótima, as restrições para cada um dos tipos i são ativas. Caso contrário, existiria necessariamente um contrato que o governo poderia oferecer especificando um pagamento maior e/ou um benefício menor, e o indivíduo aceitaria, obtendo um nível de utilidade acima da sua utilidade de reserva.

As condições de primeira ordem são dadas por:

$-1+\gamma_{i} \nu^{\prime}\left(B_{i}^{*}-g\left(p_{1}^{*}, \theta i\right)\right)=0$

$R\left(p_{1}^{*}\right)-\gamma_{i} \nu^{\prime}\left(B_{i}^{*}-g\left(p_{L}^{*}, \theta_{L}\right)\right) g_{p}\left(p_{i}^{*}, \theta_{i}\right)=0(2)$
$v\left(B_{i}^{*}-g\left(e_{i}^{*}, \theta_{i}\right)\right)=u_{i}$

onde $\gamma_{i}$ é o multiplicador de Lagrange para cada um dos respectivos tipos i de indivíduos.

Das equações 1 e 2 , temos que $R^{\prime}\left(p_{1}^{*}\right)=g_{p}\left(p_{i}^{*}, \theta_{i}\right)$. Substituindo esse resultado na equação 2 , obtemos que $1=\gamma_{i} \nu^{\prime}\left(B_{i}^{*}-g\left(p_{i}^{*}, \theta_{i}\right) \cdot \operatorname{Como}_{p \theta}(p, \theta)<0\right.$, e $R^{\prime \prime}(p)<0$ e $g_{e e}(e, \theta)>0$, então $p_{H}^{*}>p_{L}^{*}$. Observe ainda que $B_{H}^{*}>B_{L}^{*}{ }^{6}$

Esses resultados mostram que o governo consegue extrair todo o excedente dos contribuintes. Além disso, os indivíduos de alta renda, ao contribuírem mais para a Previdência, recebem também um benefício maior. A receita do governo será dada por $\lambda\left[R\left(p_{H}^{*}\right)-B_{H}^{*}\right]+(1-\lambda)\left[R\left(p_{L}^{*}\right)-B_{L}^{*}\right]$

\section{2_Quando $\theta$ não é observável}

Quando os tipos não são observáveis, aplica-se o Princípio da Revelação. O Principal procura oferecer um contrato com as seguintes condições:

a. o indivíduo anuncia o seu tipo;

b. o contrato especifica $[B(\hat{\theta}), p(\hat{\theta})]$ para cada $\hat{\theta}$ possível;

c. $\forall \hat{\theta}$ possível, a estratégia ótima do indivíduo deve ser dizer a verdade (anunciar seu tipo corretamente). 
É feita uma hipótese adicional de que o indivíduo é infinitamente avesso ao risco, o que significa que esse só aceitará um contrato que the forneça uma utilidade esperada no mínimo igual a sua utilidade de reserva.?

A única mudança no problema a ser resolvido pelo governo é quanto às restrições. Agora, além de ter de satisfazer restrições de participação dos indivíduos, o governo enfrenta restrições de compatibilidade de incentivo, ou seja, cada um dos tipos deve considerar mais vantajoso não se fazer passar pelo outro. O problema fica descrito da seguinte maneira:

$$
\begin{aligned}
& \operatorname{Max} \lambda\left[R\left(p_{H}\right)-B_{H}\right]+(1-\lambda)\left[R\left(p_{L}\right)-B_{L}\right] \\
& B_{L}, P_{L} \geq 0 \\
& B_{H}, P_{H} \geq 0 \\
& \text { s.a } \\
& \quad \text { (i) } B_{L}-g\left(p_{L}, \theta_{L}\right) \geq v^{-1}\left(u_{L}\right) \\
& \quad \text { (ii) } B_{H}-g\left(p_{H}, \theta_{H}\right) \geq v^{-1}\left(u_{H}\right) \\
& \quad \text { (iii) } B_{H}-g\left(p_{H}, \theta_{H}\right) \geq B_{L}-g\left(p_{L}, \theta_{H}\right) \\
& \quad \text { (iv) } B_{L}-g\left(p_{L}, \theta_{L}\right) \geq B_{H}-g\left(p_{H}, \theta_{L}\right)
\end{aligned}
$$

Como $u_{H}>u_{L}$, então $v^{-1}\left(u_{H}\right)>v^{-1}\left(u_{L}\right)$. Tome $\varepsilon>0 ; \varepsilon v^{-1}\left(u_{H}\right)-v^{-1}\left(u_{L}\right)$. Logo, a restrição ii pode ser reescrita como $\bar{B}_{H}-g\left(p_{H}, \theta_{H}\right) \geq v^{-1}\left(u_{L}\right)$, onde $\bar{B}_{H}=B_{H}-\varepsilon$. Dessa forma, a solução do problema torna-se similar a um problema básico de seleção adversa. A seguir são apresenta- dos alguns lemas clássicos descritos por Mas-Colell, Winston e Green (1995):

Lema 1 - Se valem as restrições $i \mathrm{e}$ iii, então ii é redundante no problema de maximização.

Lema 2 - Um contrato ótimo deve respeita a seguinte condição: $B_{L}-g\left(p_{L}, \theta_{L}\right)=v^{-1}\left(u_{L}\right)$.

Lema 3 - Em um contrato ótimo, $p_{H}=p_{H}^{*}$, onde $p_{H}^{*}$ é o resultado do problema quando os tipos são observáveis.

Lema 4 - Em um contrato ótimo, $p_{L}<p_{L}^{*}$.

Com base nos lemas 2 e 4 , temos que $B_{L}<B_{L}^{*}$. O indivíduo de renda baixa, portanto, paga uma contribuição previdenciária menor que o ótimo, mas tem seu benefício reduzido. Já o indivíduo de renda alta continua a contribuir com valor ótimo obtido do modelo de informação completa, contudo seu benefício, de acordo com a restrição ï, é maior ou igual ao benefício ótimo. Dessa forma, surge a ineficiência. A receita obtida pelo governo no modelo de informação assimétrica é menor do que a obtida no modelo de informação completa. Isso comprova que é possível aumentar a arrecadação com adoção de maior fisca-
Esta hipótese é usada com objetivo de simplificar a análise e é padrão na literatura. Ver Mas-Colell, Winston e Green (1995), capítulo 13. 
8 O cálculo do saláriobenefício era baseado nos últimos 36 meses de contribuição do trabalhador antes de sua aposentadoria. Essa regra foi mantida até a aprovação da lei que instituiu o fator previdenciário em novembro de 1999. lização no pagamento da Previdência de forma que os contribuintes não omitam sua renda verdadeira. Essa queda na arrecadação líquida certamente é menor para a faixa de indivíduos de baixa renda em relação aos de alta.

\subsection{O efeito da Constituição de 1988}

A Constituição de 1988 alterou de forma significativa os incentivos dos indivíduos em participar da Previdência Social. De forma geral, a população, sobretudo a de baixa renda, obteve uma série de benefícios sem que obrigações lhe fossem impostas. Alguns desses benefícios, como o serviço público de saúde, deixaram de ser limitados aos contribuintes e foram estendidos a toda a população. Além disso, a nova Constituição elevou de $1 / 2$ para 1 salário mínimo o valor do benefício assistencial, a que todo cidadão, rural ou urbano, tem direito independentemente de ter contribuído para a Previdência.

Utilizando o modelo de informação assimétrica desenvolvido na seção anterior, podem-se reescrever as restrições de participação dos dois tipos de indivíduo, de modo a incorporar algumas das mudanças introduzidas pela nova Constituição:

Antes da Constituição de 1988

$$
\begin{aligned}
& v\left(S P+S B_{H}-g\left(p_{H}, \theta_{H}\right)\right) \geq u_{H} \\
& v\left(S P+S B_{L}-g\left(p_{L}, \theta_{L}\right)\right) \geq u_{L}=S M / 2
\end{aligned}
$$

Depois da Constituição de 1988

$$
\begin{aligned}
& v\left(S B_{H}-g\left(p_{H}, \theta_{H}\right)\right) \geq u_{H} \\
& v\left(S B_{L}-g\left(p_{L}, \theta_{L}\right)\right) \geq u_{L}=S M
\end{aligned}
$$

Onde SP representa o acesso ao serviço público de saúde, $S B$ é o saláriobenefício do segurado do tipo $i$ e $S M$ representa o salário mínimo. ${ }^{8}$ Nota-se que, após a Constituição de 1988, a saúde pública deixa de ser um benefício da Previdência Social e há uma elevação da utilidade de reserva do indivíduo de renda mais baixa com o aumento do salário assistencial.

Como a nova Constituição impôs poucas obrigações em relação aos benefícios estendidos a toda a população, supõe-se que as contribuições, $g\left(p_{i}, \theta_{i}\right)=g\left(p_{i}^{*}, \theta_{i}\right)$, não se alteraram, ao contrário dos benefícios, $B_{i}$, e a utilidade de reserva dos indivíduos de baixa renda, $u_{L}$. É de se esperar que tanto os indivíduos de alta como os de baixa renda tenham agora menos incentivos a participar da Previdência Social. Esses incentivos são ainda mais intensos para os mais pobres já que obtiveram também um incremento em sua utilidade de reserva, e sua restrição de participação é ativa no problema de maximização.

Portanto, essas mudanças do sistema de Previdência deveriam ter sido acompanhadas de modificações nas contribuições exigidas, ou seja, o governo deveria elaborar 
novos contratos de previdência a partir das restrições de participação modificadas. Essa alternativa talvez seja mais difícil de ser implementada em relação a imposição de uma fiscalização mais rígida na declaração de renda para fins de contribuição previdenciária proposta na seção anterior, já que necessita de aprovação do Congresso.

\section{4_Análise empírica}

Existem diversas pesquisas que possibilitam um levantamento de dados apropriado para a obtenção de informações de cada indivíduo da população: quantos contribuem, quem contribui, qual a intensidade da contribuição e como se comportam os indivíduos em pequenos negócios (conta-própria). As mais utilizadas para esse fim são a Pesquisa Nacional por Amostras de Domicílios (PNAD), a Pesquisa Orçamentária Familiar (POF) e a Economia Informal Urbana (ENCIF).

A PNAD será a principal fonte de dados aqui utilizada. Anualmente, ela atinge 100.000 domicílios por todo o território nacional à exceção das áreas rurais de Rondônia, Acre, Roraima, Pará e Amapá. ${ }^{9}$ Essa base de dados tem a vantagem de possuir uma série de perguntas sobre previdência, além de conseguir cobrir o setor informal da economia, disponibilizando as estimativas de informações que o próprio Ministério da Previdência não dispõe. Valendose dos dados referentes a 1985, 1990, 1992, 1993, 1996 e 1999, analisou-se o efeito da Constituição de 1988 sobre a decisão dos indivíduos em participar do sistema de Previdência pública (INSS). Em razão da grande dimensão dos dados, utilizou-se apenas os indivíduos contas-próprias que correspondem cerca de $20 \%$ dos potenciais participantes da Previdência (Tabela 2). Esses indivíduos autônomos correspondem à classe de trabalhadores que não têm vínculo empregatício. Dessa forma, a decisão em participar do sistema previdenciário depende exclusivamente dele.

Utilizando-se o método de regressão logística, é possível identificar o peso das principais variáveis relacionadas à não-contribuição previdenciária como sexo, posição do indivíduo dentro da família, idade, educação, renda, entre outras. ${ }^{10}$ Para cada ano, foi feita uma regressão cuja variável independente é igual a 1 , se o indivíduo de conta-própria não contribuiu para a Previdência, e zero, caso contrário. Em todos os anos, os estimadores são significantes. Além disso, chama a atenção o fato de o peso na não-contribuição ser maior conforme a renda.

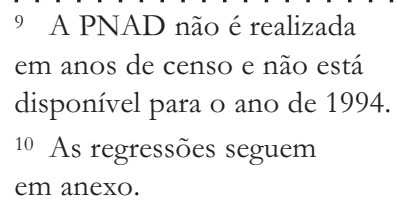



11 Todos os gráficos estão dispostos ao final do trabalho.

12 A classificação do domicílio é urbana ou rural segundo a sua área de localização e tem por base a legislação vigente por ocasião da realização do Censo Demográfico de 1991. Como situação urbana, consideram-se as áreas correspondentes às cidades (sedes municipais), às vilas (sedes distritais) ou às áreas urbanas isoladas. A situação rural abrange toda a área situada fora desses limites. Esse critério é também utilizado na classificação da população urbana e rural. Foi usado na classificação o rural não metropolitano.

13 Vale lembrar que a interpretação das razões de chance é feita da seguinte forma: se o primeiro quintil de renda tem uma razão de chances de 7,99. Isso significa que um conta-própria nessa faixa de renda tem $699 \%$ mais de chance de não contribuir para a Previdência que um conta-própria no quinto quintil (variável omitida).
No Gráfico 1, observa-se que a porcentagem dos contas-próprias que não contribuem para a Previdência tem subido continuamente após a Constituição de 1988. Em 1985, 77,5\% desses indivíduos não participavam do sistema previdenciário e, em 1999, esse número subiu para $84,6 \% .{ }^{11}$ Contudo, ocorreram mudanças no perfil dos contas-próprias ao longo de todo o período. $\mathrm{O}$ trabalhador autônomo tem se tornado cada vez mais urbano e menos rural, tem trabalhado menos com agricultura e mais com serviços e está cada vez mais educado e mais velho. Essas alterações de perfil podem ser vistas nos Gráficos 2, 3, 4 e $5 .{ }^{12}$ A porcentagem dos trabalhadores autônomos que não contribuem para a Previdência aumentou em todos os setores de atividade, níveis de escolaridade e faixas etárias. Esses dados refletem uma tendência generalizada de queda da participação no INSS.

As alterações na restrição de participação do trabalhador descritas anteriormente sugerem mudanças de comportamento para aqueles nos quintis mais baixos de renda, para quem essas restrições estavam ativas (Gráficos 6 e 7). Entretanto, o que de fato se observou foi um movimento abrangente e contínuo de queda na con- tribuição. Analisando-se especificamente a proporção de contas-próprias não contribuintes por quintis de renda, é possível notar que, apesar de os mais ricos contribuírem mais, esses constituem o grupo que mais está saindo do sistema. Nota-se que o quinto quintil tem a maior evolução percentual de não-contribuição entre todas as faixas de renda. Por essa ótica, observamse evidências compatíveis com a Teoria da Renda Permanente de Friedman e o Modelo de Ciclo de Vida de Modigliani. Os trabalhadores procuram suavizar seu consumo e, naturalmente, quem tem mais renda poupa relativamente mais.

Quando se observa a evolução das razões de chance condicionais ao longo do tempo (Gráfico 7), fica claro que a diferença entre os estimadores do primeiro quintil é significativamente maior que a do quarto quintil. Esse resultado é bastante informativo quanto à importância da faixa de renda na decisão em contribuir para o sistema de Previdência, uma vez que todas as outras variáveis, como idade, escolaridade e setor de atividade, estão sendo controladas. Além disso, essa diferença se mantém praticamente inalterada $(7,99$ para o primeiro quintil contra 1,66 para o quarto quintil em $1985 \mathrm{e}$ 7,32 contra 1,88 em 1999). ${ }^{13}$ 
Gráfico 1_Porcentagem de não contribuição dos conta-própria

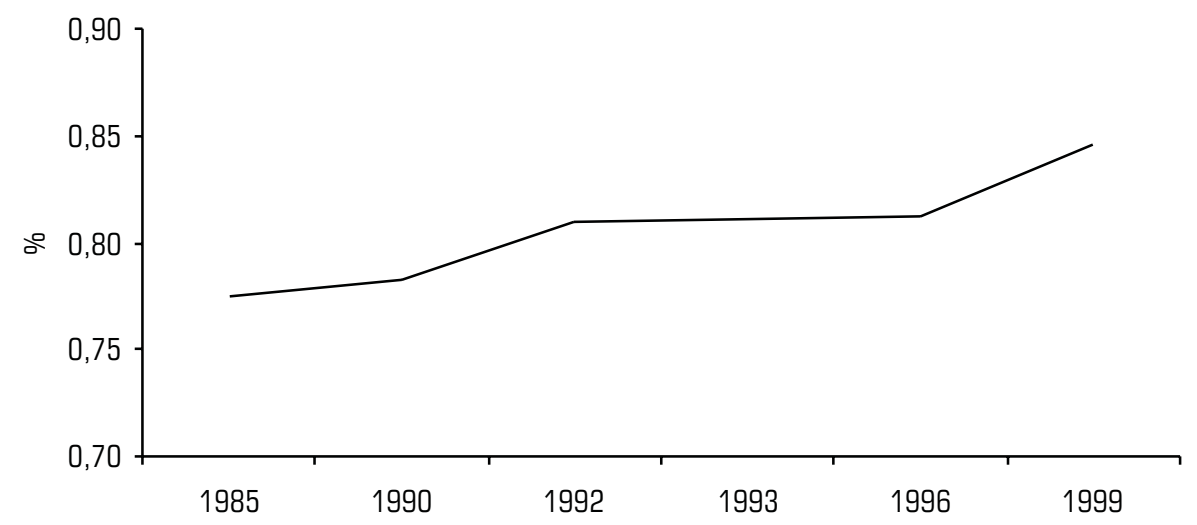

Fonte: PNAD/IBGE. Elaboração: CPS/IBRE/FGV.

\section{Gráfico 2_Distribuição percentual de autônomos rurais e urbanos}

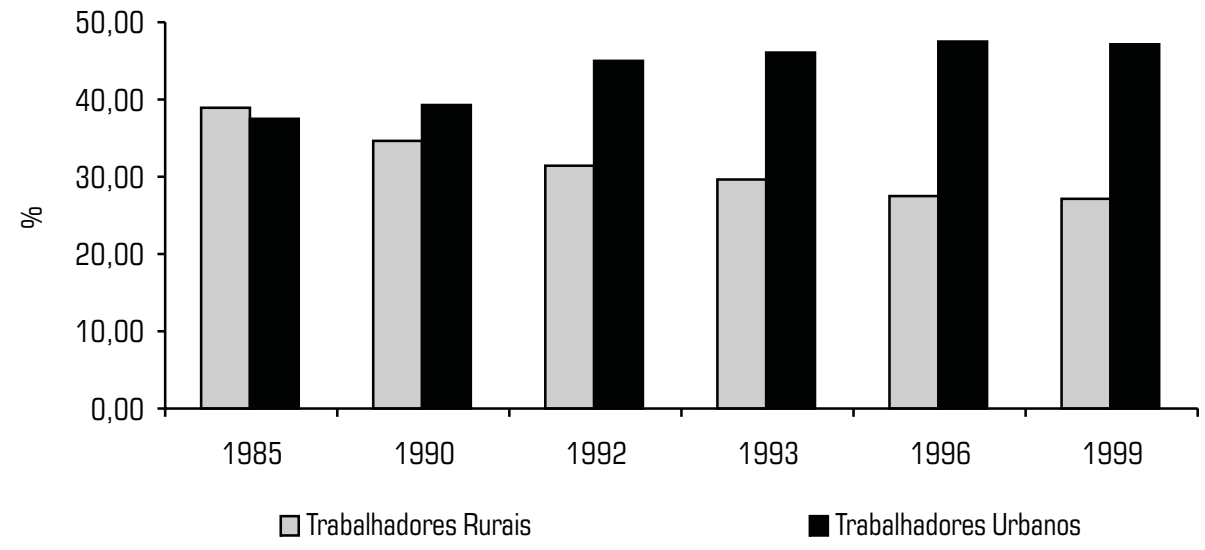

Fonte: PNAD/IBGE. Elaboração: CPS/IBRE/FGV. 
Gráfico 3_ Distribuição dos contra-própria por setor de atividade

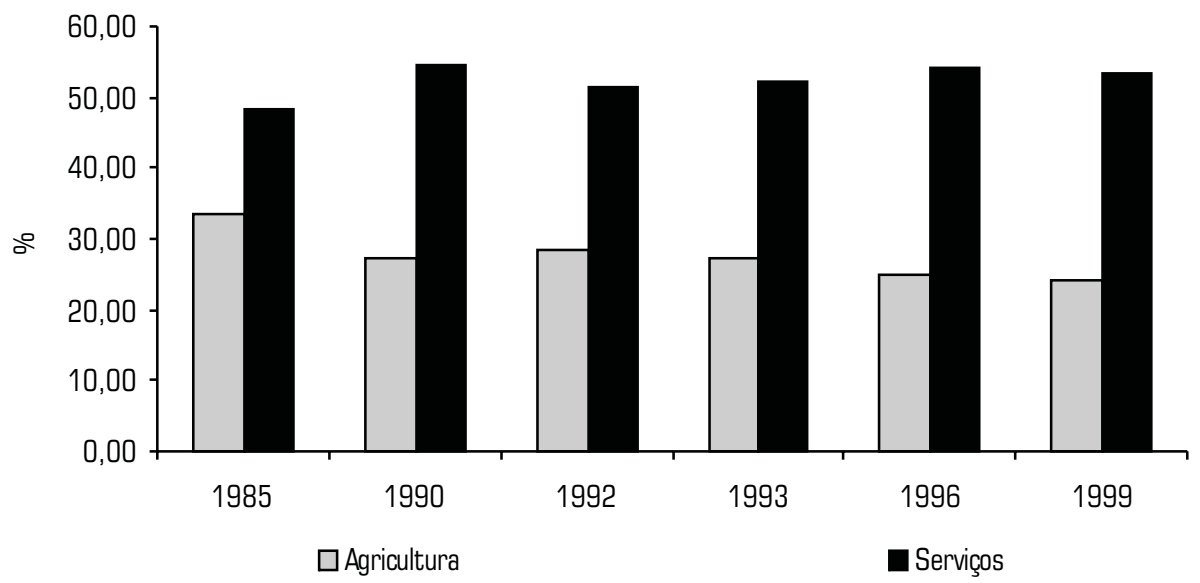

Fonte: PNAD/IBGE. Elaboração: CPS/IBRE/FGV.

Gráfico 4_Distribuição dos autônomos de acordo com a escolaridade

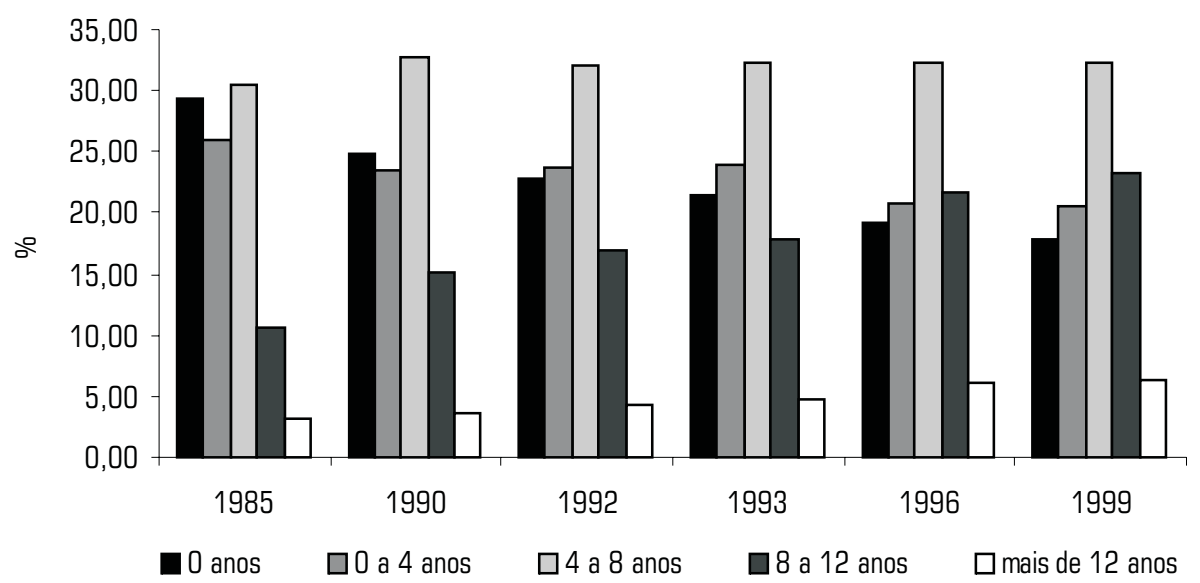

Fonte: PNAD/IBGE. Elaboração: CPS/IBRE/FGV. 
Gráfico 5_ Distribuição percentual dos autônomos por faixa etária

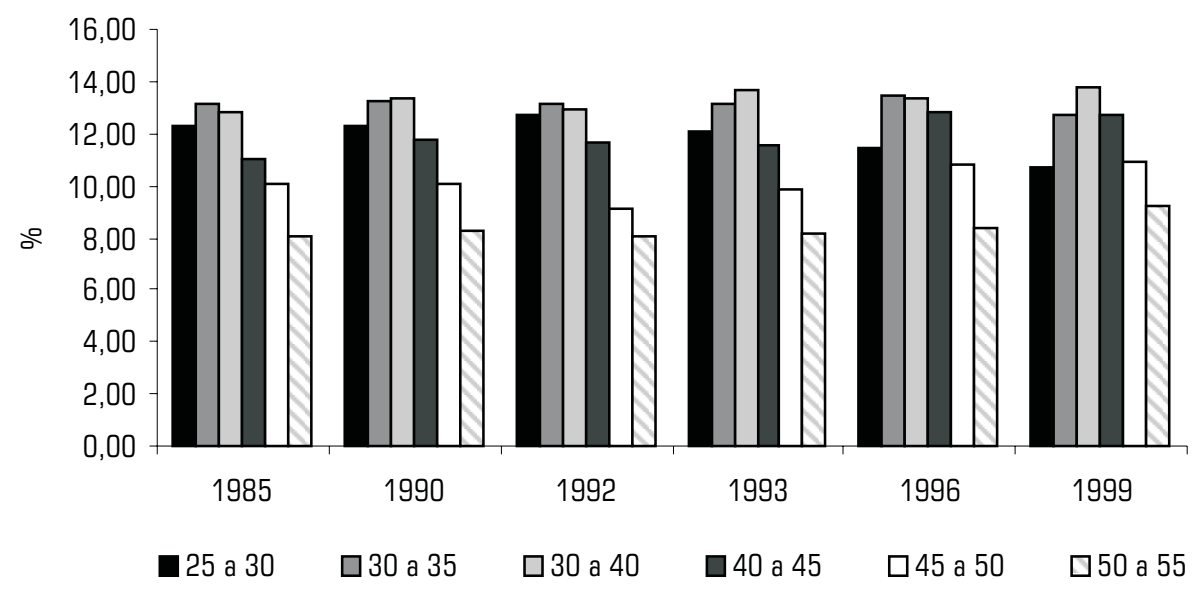

Fonte: PNAD/IBGE. Elaboração: CPS/IBRE/FGV.

Gráfico 6_ A evolução não-contribuição por quintil de renda

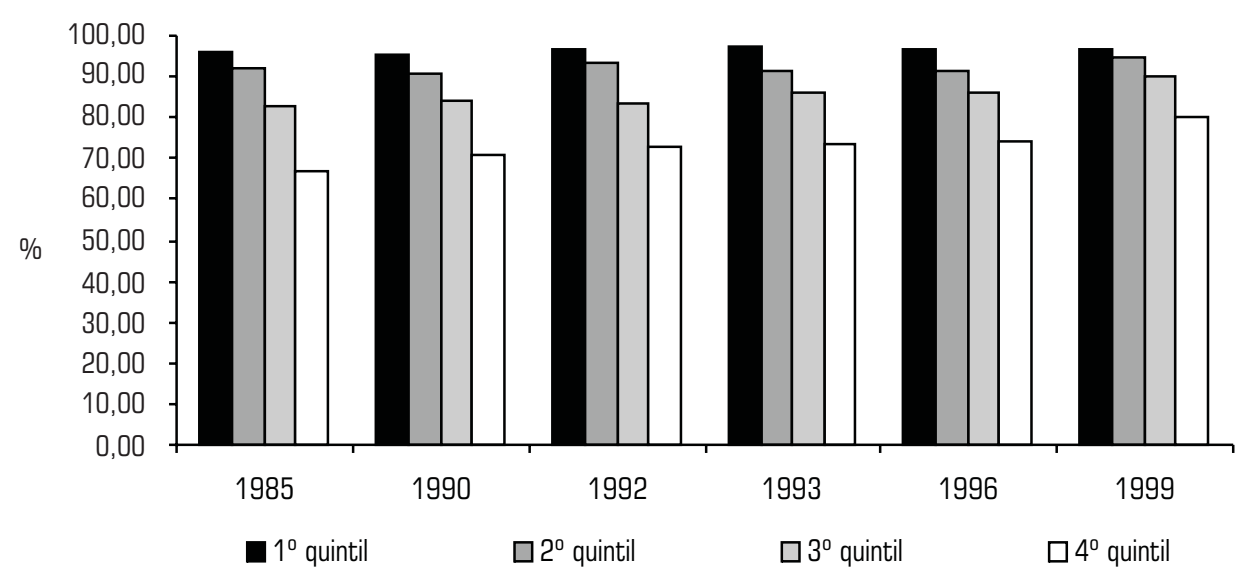

Fonte: PNAD/IBGE. Elaboração: CPS/IBRE/FGV. 


\section{Gráfico 7_ Evolução das razões de chance condicionais com relação ao quinto quintil}

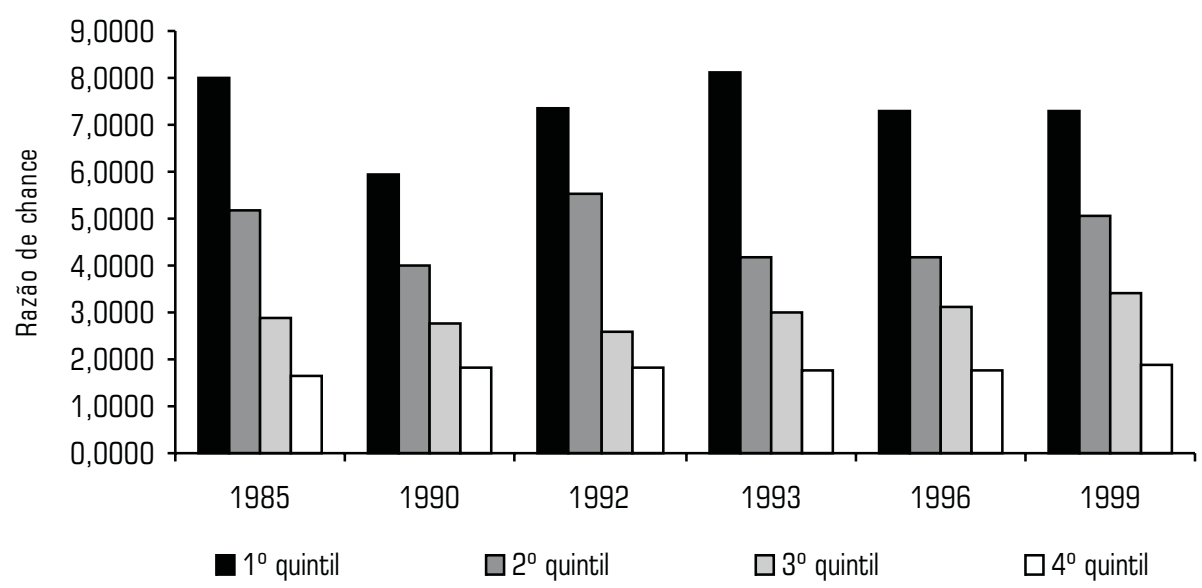

Fonte: PNAD/IBGE. Elaboração: CPS/IBRE/FGV.

A análise dos dados contradiz a previsão do modelo de que a queda da participação no sistema de Previdência, dado a nova Constituição, seria resultado da mudança de comportamento dos contas-próprias de menor renda, para quem a restrição de participação estaria ativa. Contudo, há uma diminuição na participação no sistema previdenciário mais acentuadas paras as faixas de renda mais altas. Uma possível explicação é a simplicidade do modelo teórico utilizado já que não incorporam outras variáveis que determinam a decisão dos indivíduos em participar da Previdência como escolaridade, idade, sexo, existências de outros fundos de previdência concorrentes, entre outras.
Mas um modelo que incorporasse todos os fatores que dete rmina a decisão em participar do sistema de Previdência seria muito complexo e trabalhoso.

Em termos teóricos, a saída dos contas-próprias de renda alta do sistema representa uma violação da restrição de compatibilidade de incentivos. Apesar de a restrição de participação não estar ativa para eles, comportam-se como se fossem do tipo de renda baixa e optam por deixar o sistema de Previdência.

É interessante lembrar que a decisão de poupança do trabalhador autônomo tem sido objeto de estudo há décadas. Friedman (1957) relacionou evidências dos 
anos 50 de que os contas-próprias poupariam mais do que outras classes de trabalhadores com o alto risco de renda da profissão (que incentivaria uma maior poupança precaucional) associado a altas taxas de retorno (parte dessa poupança seria na verdade reinvestimentos no seu próprio negócio, sem a presença de intermediários). Skinner (1988) construiu um modelo para estudar a decisão de poupança precaucional como função do risco de renda e de taxa de juros. Apesar de o conta-própria ter mais incerteza quanto a sua renda do que outros tipos de trabalhador, as evidências apresentadas nesse mesmo artigo (baseadas em pesquisas dos anos 70) contradizem o modelo. Uma das possíveis explicações apresentadas por Skinner é a de que o alto risco de renda do conta-própria geraria uma auto-seleção de pessoas mais propensas ao risco, o que implicaria menor poupança precaucional.

No presente trabalho, a evidência empírica também contraria as previsões do modelo. A razão por que se reduziu expressivamente a poupança (contribuição para a Previdência) dos mais ricos não está clara, mas pode estar associada a um "efeito composição". O grupo dos contas-próprias estaria crescendo com uma participação cada vez maior de trabalhadores que não desejam poupar (tornam-se conta- própria justamente para não serem obrigados a contribuir para a Previdência). Esse fenômeno poderia estar relacionado com a idéia de auto-seleção levantada por Skinner. Não se pode negligenciar, contudo, a atual competição da previdência pública com fundos privados de previdência. Isso certamente se traduz em um aumento no custo de oportunidade de contribuição.

\section{C Conclusão}

Os crescentes déficits no sistema público de Previdência são em parte resultado de um processo de informalização da economia. A parcela de trabalhadores autônomos é cada vez maior, bem como o número dos que optam por não contribuir para o INSS.

Este trabalho propôs uma abordagem para esse problema diferente do que tem sido apresentado sobre a literatura. Com base em um arcabouço de Principal e Agente, modelaram-se os incentivos dados aos trabalhadores para que participassem do sistema previdenciário. Dessa forma, foi possível verificar que uma fiscalização mais rígida quanto à declaração de renda para fins de contribuição previdenciária pode gerar aumento de receita para o governo.

Além disso, analisaram-se as mudanças introduzidas pela Constituição de 
1988 sobre a Previdência Social. Em geral, indivíduos com rendas mais baixas receberam relativamente mais incentivos a não participar da Previdência. Contudo, esse fato não foi comprovado pela evidência empírica apresentada. Ao contrário do modelo teórico desenvolvido, indivíduos de conta-própria com rendas mais altas diminuíram relativamente mais sua participação no sistema da Previdência.

$\mathrm{O}$ afastamento desses trabalhadores autônomos mais ricos do sistema público de Previdência pode ser fruto de um efeito composição ou então de uma quebra desse monopólio, no sentido de já estarem disponíveis no mercado opções confiáveis de fundos de previdência privados. Neste caso seria interessante repensar o modelo como uma competição de principais. Cabe lembrar que fundos de previdência privados não constituem uma opção de previdência para os trabalhadores nos quintis de renda mais baixos. Ainda assim, é razoável dizer que o conjunto de incentivos que levou esses trabalhadores a sair do sistema se mantém uma questão em aberto.

Em termos de incentivos para os autônomos mais pobres, Neri (1998) organizou os resultados de uma pesquisa feita com microempresários da Favela da Rocinha, no Rio de Janeiro. A precariedade de acesso a crédito torna a poupança um bem de luxo. Isso significa que contribuir para o INSS tem um alto custo de oportunidade. Contudo, esse custo poderia ser atenuado com o desenvolvimento de políticas de microcrédito (condicionado à inscrição no INSS) que levassem em consideração o benefício de aumentar a renda disponível para poupança dos trabalhadores e os custos de implementação e inadimplência. 


\section{Referências bibliográficas}

CAMARANO, Ana Amélia, et al. Como vive o idoso brasileiro? Muito além dos 60 - os novos idosos brasileiros. Capítulo 2. IPEA, 1999.

DART, Samantha. Reformo Previdenciária: em busca de incentivos para atrair o trabalhador autônomo para Previdência Social. 2000.

Dissertação (Mestrado)

- EPGE. Rio de Janeiro, 2000.

FRIEDMAN, Milton. A theory of the consumption function. NBER, n. 63, General Series, 1957.

GIAMBIAGI, Fábio; ALÉM, Ana Cláudia. Finanças Públicas Teoria e Prática no Brasil. Ed. Campos, 2000.

GIAMBIAGI, Fábio; ALÉM, Ana Cláudia; PASTORIZA, Florinda. A aposentadoria por tempo de serviço no Brasil: estimativa do subsídio recebido pelos seus beneficiários. Revista Brasileira de Economia, v. 52, n. 1, 1998

GRAMLICH, Edward. Different approaches for dealing with social security. The American Economic Review. San Francisco, maio, p. 358-362, 1996.

IBGE. Pesquisa Nacional de Amostra por Domicílios, 1997.

IBGE. Pesquisa Nacional por amostras de Domicílios (PNAD, 1999), microdados.
KANDIR, Antônio et al. Previdência social: a experiência internacional. In: A previdência social e a revisão constitucional. Brasília: MPS, cap. 4, v. 4, 1994

MARQUES, Rosa Maria; BATICH, Mariana. Os impactos da evolução recente do mercado de trabalho no financiamento da Previdência Social. Conjuntura Social, v. 10, n. 4, p. 122-136, out.-dez. 1999.

MAS-COLELL, Andreu; WINSTON, Michael; GREEN, Jerry. Microeconomic Theory. Oxford Press, 1995.

MINISTÉRIO DA PREVIDÊNCIA E ASSISTÊNCIA SOCIAL.

Anuário Estatístico da

Previdência Social -

Suplemento Estatístico, 1999.

NERI, Marcelo. Os empresários da Rocinha. Rio de Janeiro, 1998.

NERI, Marcelo. Cobertura previdenciária: diagnóstico e propostas. Ministério da Previdência e Assistência Social. Coleção Previdência Social, Série Estudos, v. 18, Brasília, 2003.

OLIVEIRA, Francisco Eduardo Barreto. Basic Issues in Reforming Social Security Systems, IPEA, 1997. (Texto para Discussão, 535).
OLIVEIRA, Francisco; BELTRÃO, Kaizô. O idoso e a Previdência Social. Muito além dos 60 - os novos idosos brasileiros. Capítulo 10. IPEA, 1999.

ORNÉLAS, Waldeck; VIEIRA, Solange. As novas regras da Previdência Social. Conjuntura Econômica, p. 18-22, nov. 1999. ORNELAS, Waldeck; VIEIRA, Solange. Novo rumo para a Previdência brasileira, Conjuntura Social, v.10, n. 4 p. 7-25, out.-dez. 1999.

PAGE, Frank. Competitive selling mechanisms: the delegation principle and farsighted stability, 1998. Mimeogr.

RONDANELLI, Erik. Chilean pension fund reform and its impact on saving. Santiago de Chile: Universidad Gabriela Mistral. 1996. Mimeogr.

SKINNER, Jonathan. Risky income, life cycle consumption, and precautionary savings. Journal of Monetary Economics, n. 22 p. $237-255,1988$

STIGLITZ, Joseph E.; WEISS, Andrew. Credit rationing in markets with imperfect information. American Economic Review, n. 71, p. 393-410, 1981.
SUIJS, Jeroen; WAEGENAERE Anja; BORM, Peter. Optimal design of pension funds: A mission impossible? Center of Economic Research, Tilburg University, 1998.

WILLIANS, David. Fora da Seguridade Social? Os trabalhadores autônomos: Previdência Social para aqueles que provêm sua própria ocupação. Conjuntura Social, v. 10 , n. 4, p. 137-165, out.-dez. 1999.

WORLD BANK. Brazil Critical Issues in Social Security. Volume II: Policy Report. 2000.

(Relatório, 19641-BR).

Agradecemos os comentários,
: críticas e sugestões de Kaizố
: Beltrão e aqueles apresentados
$:$ Brasileira de Econometria.
$:$ E-mail de contato dos autores:
$:$ meneri@fgv.br
$:$ artite@fgr.br
aprovado em outubro de 2006.


Anexo

Modelo Logístico, análise dos parâmetros estimados 1985 - Não Contribui para a Previdência - Conta-Própria

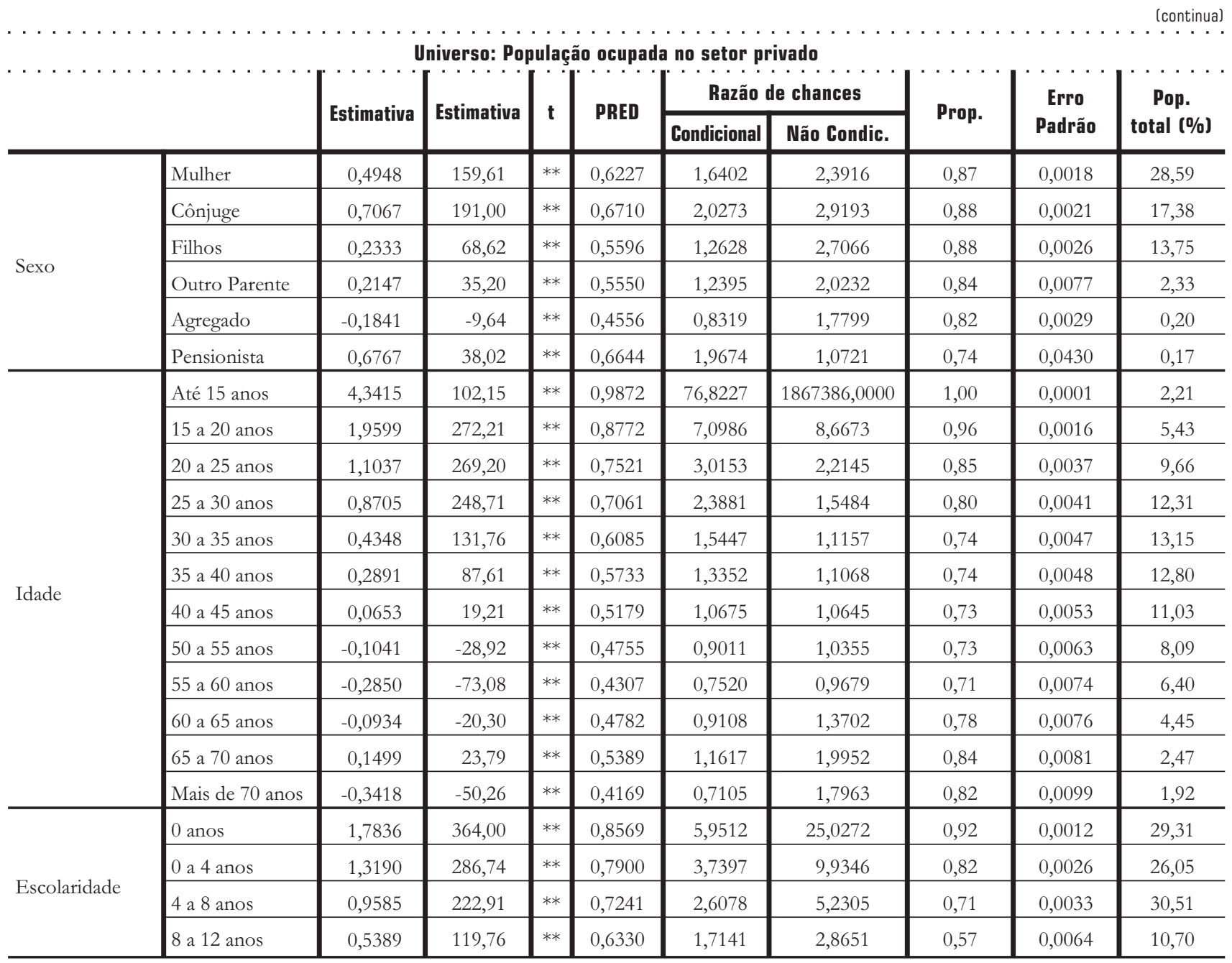


Modelo Logístico, análise dos parâmetros estimados 1985 - Não Contribui para a Previdência - Conta-Própria

Universo: População ocupada no setor privado

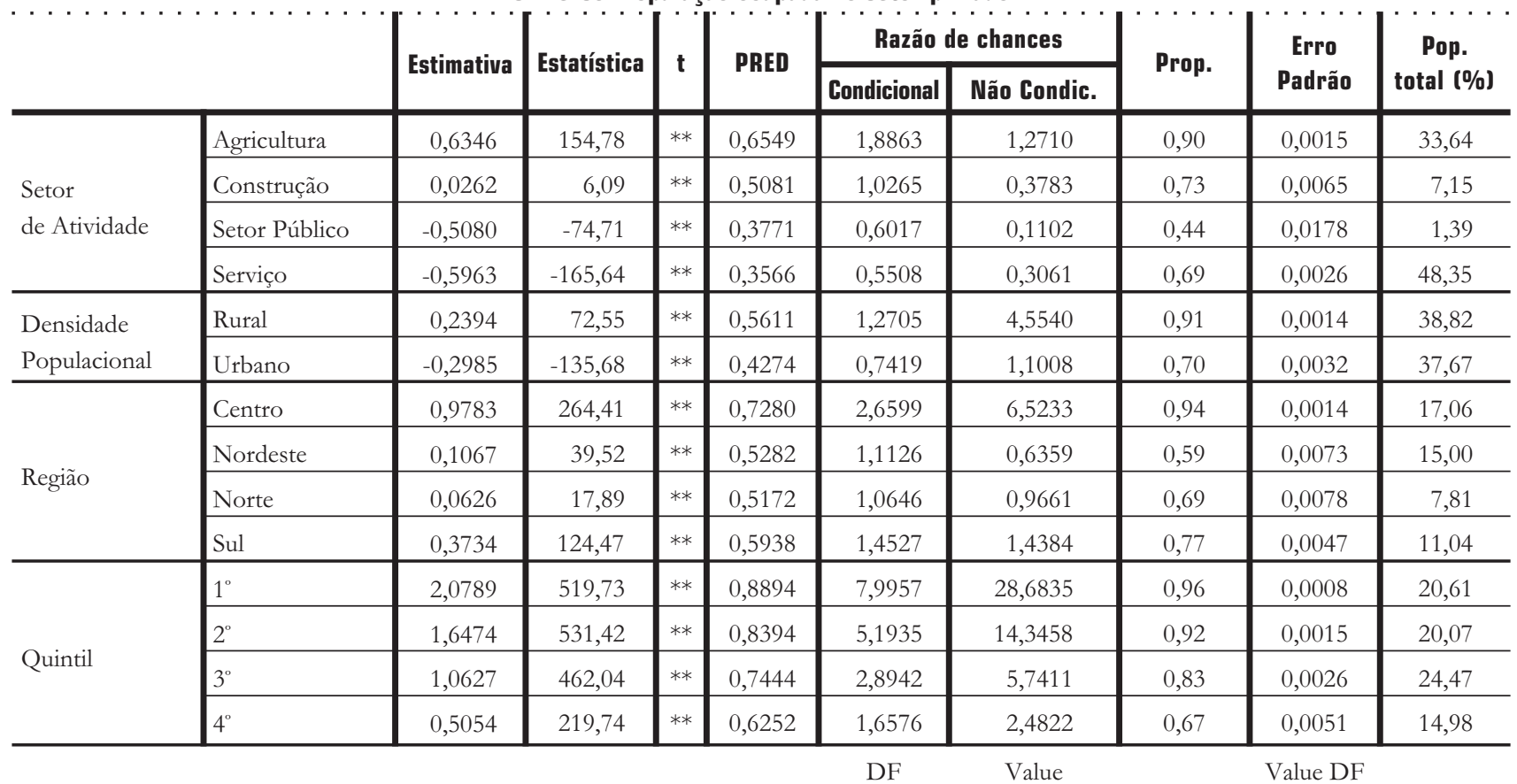

Value DF

Número de Observações: 47350; Log Likelihood: -4578466.197; Pearson Chi-Square: 15000 47177229 286

(*) Estatisticamente significante ao Nível de Confiança de $90 \%$

(**) Estatisticamente significante ao Nível de Confiança de $95 \%$

Fonte: IBGE. Pesquisa Nacional por amostras de Domicílios (PNAD, 1999), microdados. Elaboração: CPS/IBRE/FGV

Obs: Variáveis omitidas em ordem: homem, chefe de Família, idade entre 45 e 50 anos, mais de 12 anos de estudo completos, setor industrial, metropolitano, região sudeste, $5^{\circ}$ quintil.

\begin{tabular}{|c|c|c|}
\hline \multicolumn{2}{|c|}{$N^{0}$ de Pessoas } & $\%$ \\
\hline Não Contribui & 9.478 .948 & 77,5 \\
\hline Contribui & 2.745 .046 & 22,5 \\
\hline
\end{tabular}


Modelo Logístico, análise dos parâmetros estimados 1990 - Não Contribui para a Previdência - Conta-Própria

(continua)

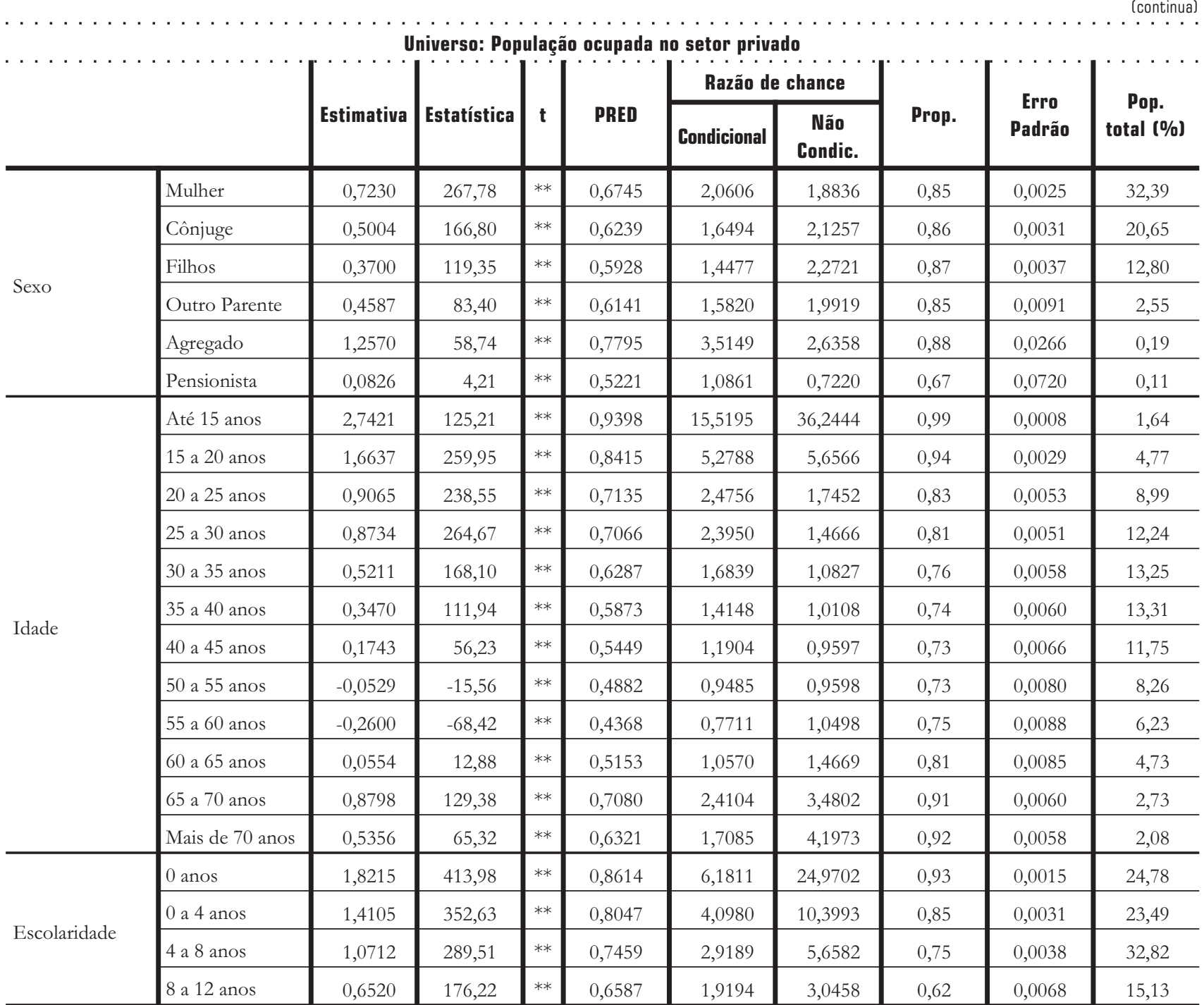


Modelo Logístico, análise dos parâmetros estimados 1985 - Não Contribui para a Previdência - Conta-Própria

(conclusão)

Universo: População ocupada no setor privado

\begin{tabular}{|c|c|c|c|c|c|c|c|c|c|c|}
\hline & & 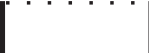 & ( & 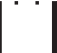 & & Razão de & chance & & 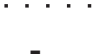 & 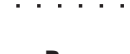 \\
\hline & & Estimativa & Estatística & $\mathbf{t}$ & PRED & Condicional & $\begin{array}{c}\text { Não } \\
\text { Condic. }\end{array}$ & Prop. & $\begin{array}{c}\text { Erro } \\
\text { Padrão }\end{array}$ & $\begin{array}{c}\text { Pop. } \\
\text { total (\%) }\end{array}$ \\
\hline & Agricultura & 0,9619 & 223,70 & $* *$ & 0,7246 & 2,6167 & 2,3519 & 0,95 & 0,0012 & 27,31 \\
\hline Setor & Construção & 0,1300 & 31,71 & $* *$ & 0,5339 & 1,1388 & 0,4100 & 0,75 & 0,0075 & 8,27 \\
\hline & Serviço & $-0,6713$ & $-191,80$ & $* *$ & 0,3395 & 0,5110 & 0,3153 & 0,70 & 0,0032 & 54,60 \\
\hline Densidade & Rural & 0,3096 & 103,20 & $* *$ & 0,5782 & 1,3629 & 6,8252 & 0,93 & 0,0014 & 34,71 \\
\hline Populacional & Urbano & $-0,1176$ & $-61,89$ & $* *$ & 0,4721 & 0,8891 & 1,4349 & 0,74 & 0,0037 & 39,44 \\
\hline & Centro & 1,0331 & 264,90 & $* *$ & 0,7386 & 2,8098 & 5,4999 & 0,95 & 0,0015 & 15,00 \\
\hline 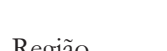 & Nordeste & $-0,1704$ & $-71,00$ & $* *$ & 0,4589 & 0,8433 & 0,4325 & 0,60 & 0,0093 & 16,87 \\
\hline Intgiau & Norte & $-0,3363$ & $-108,48$ & $* *$ & 0,4181 & 0,7144 & 0,5360 & 0,65 & 0,0109 & 8,44 \\
\hline & Sul & $-0,3331$ & $-123,37$ & $* *$ & 0,4189 & 0,7167 & 0,7794 & 0,73 & 0,0066 & 11,57 \\
\hline & $1^{\circ}$ & 1,7796 & 508,46 & $* *$ & 0,8564 & 5,9275 & 24,2965 & 0,95 & 0,0011 & 21,34 \\
\hline . in & $2^{\circ}$ & 1,3876 & 495,57 & $* *$ & 0,8011 & 4,0052 & 11,5699 & 0,91 & 0,0023 & 19,35 \\
\hline रूuinul & $3^{\circ}$ & 1,0081 & 420,04 & ** & 0,7338 & 2,7404 & 6,3947 & 0,84 & 0,0033 & 21,21 \\
\hline & $4^{\circ}$ & 0,5955 & 283,57 & $* *$ & 0,6459 & 1,8139 & 2,8923 & 0,71 & 0,0052 & 21,05 \\
\hline
\end{tabular}

DF Value

Value DF

Número de Observações: 28738; Log Likelihood: -5252355,55; Pearson Chi-Square: $12000 \quad 6521333$

(*) Estatisticamente significante ao Nível de Confiança de $90 \%$

(**) Estatisticamente significante ao Nível de Confiança de $95 \%$

Fonte: IBGE. Pesquisa Nacional por amostras de Domicílios (PNAD, 1999), microdados. Elaboração: CPS/IBRE/FGV.

Obs: Variáveis omitidas em ordem: homem, chefe de Família, idade entre

45 e 50 anos, mais de 12 anos de estudo completos, setor industrial,

metropolitano, região sudeste, $5^{\circ}$ quintil.

\begin{tabular}{|c|c|c|}
\hline Não Contribui & 11.033 .049 & 78,3 \\
\hline Contribui & 3.058 .029 & 21,7 \\
\hline
\end{tabular}


Modelo Logístico, análise dos parâmetros estimados 1992 compatível década 80 - Não Contribui para a Previdência - Conta-Própria

(continua)

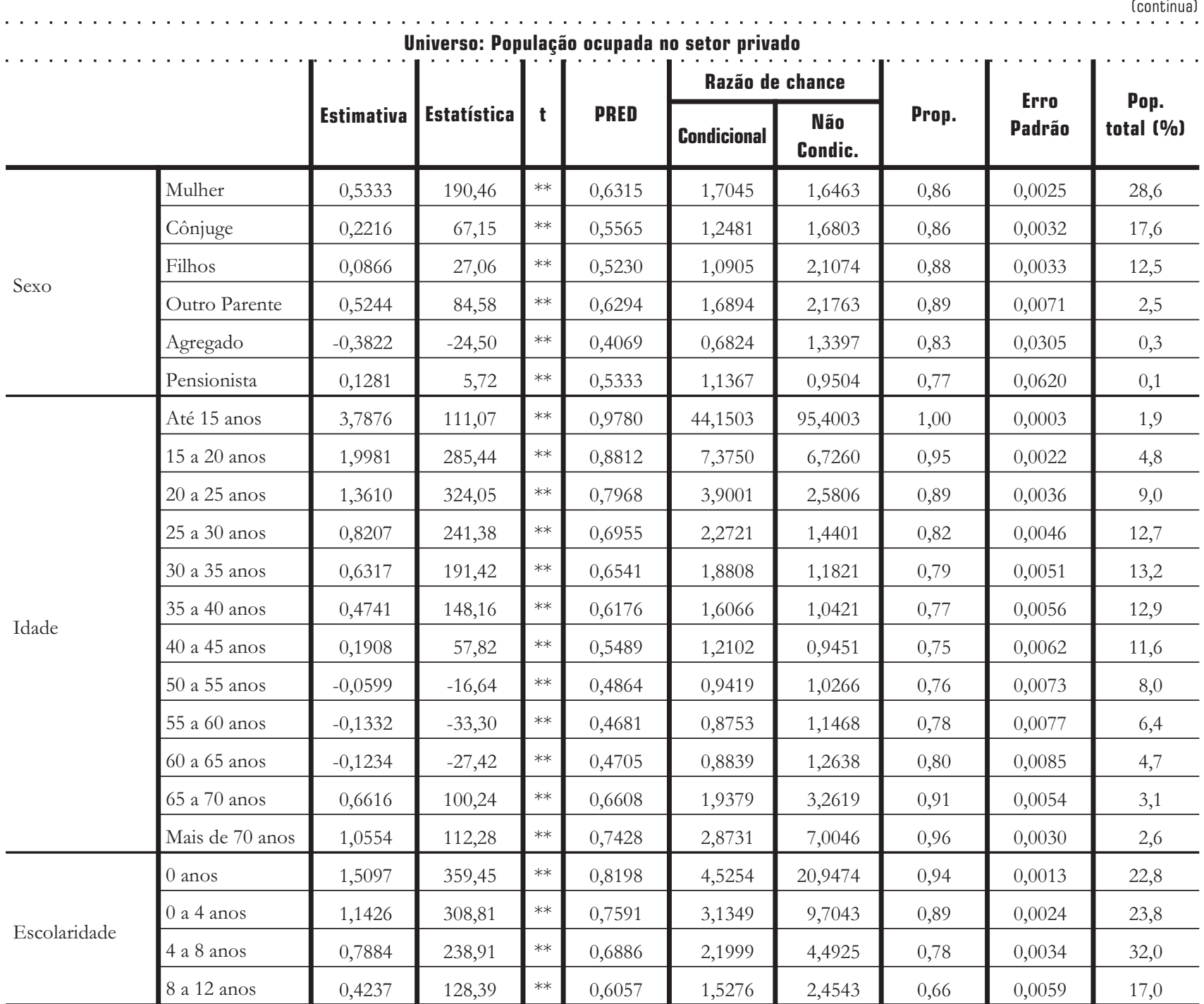


Modelo Logístico, análise dos parâmetros estimados 1992 compatível década 80 - Não Contribui para a Previdência - Conta-Própria

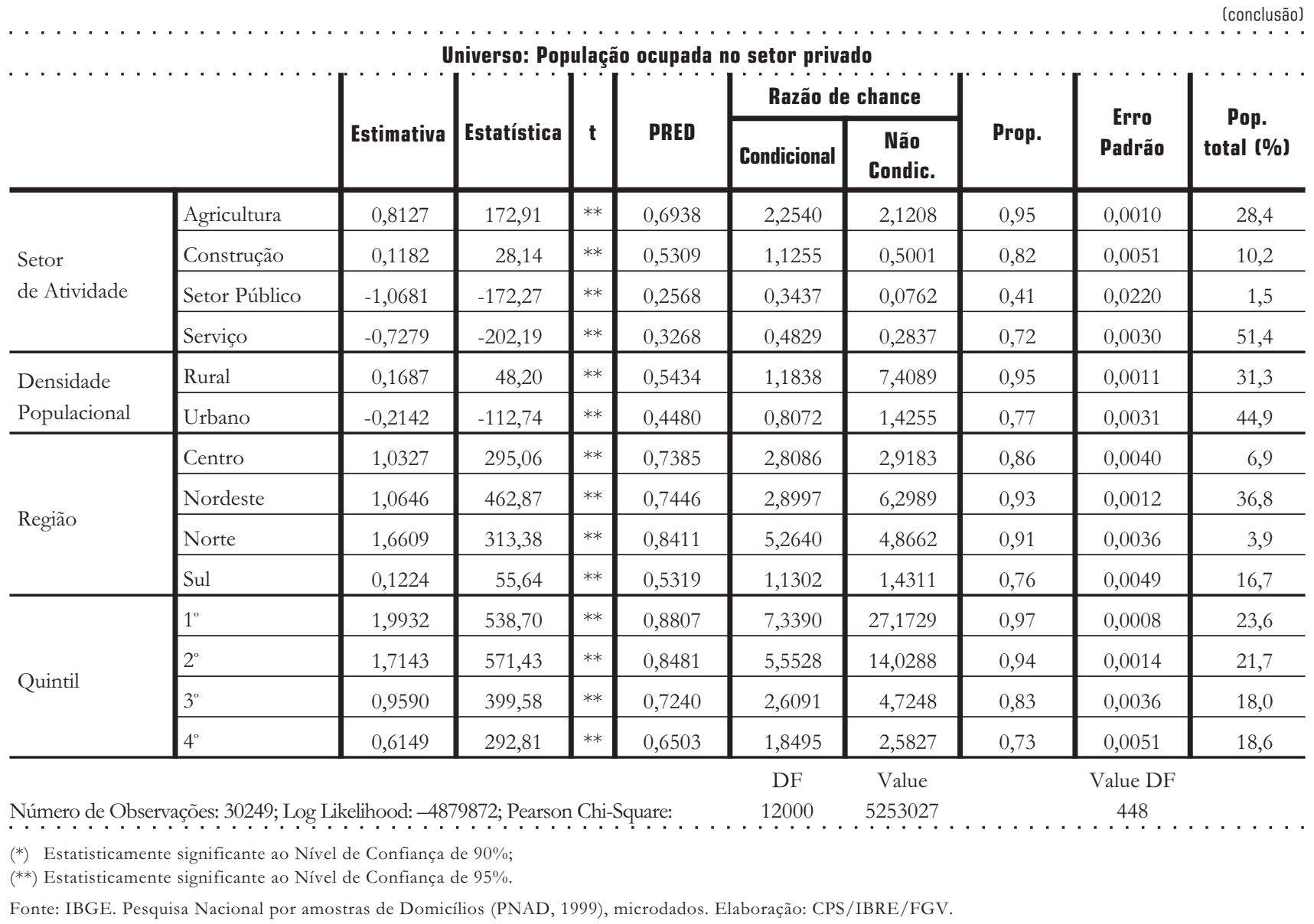

Obs: Variáveis omitidas em ordem: homem, chefe de Família, idade entre 45 e 50 anos, mais de 12 anos de estudo completos, setor industrial, metropolitano, região sudeste, $5^{\circ}$ quintil.

\begin{tabular}{l|c|c}
\multicolumn{2}{|c|}{$\mathbf{N}^{\circ}$ de Pessoas } & $\%$ \\
\hline Não Contribui & 11.490 .748 & 81,0 \\
\hline Contribui . . . . . . . . . . . . . . . . .
\end{tabular}


Modelo Logístico, análise dos parâmetros estimados 1993 compatível década 80 - Não Contribui para a Previdência - Conta-Própria

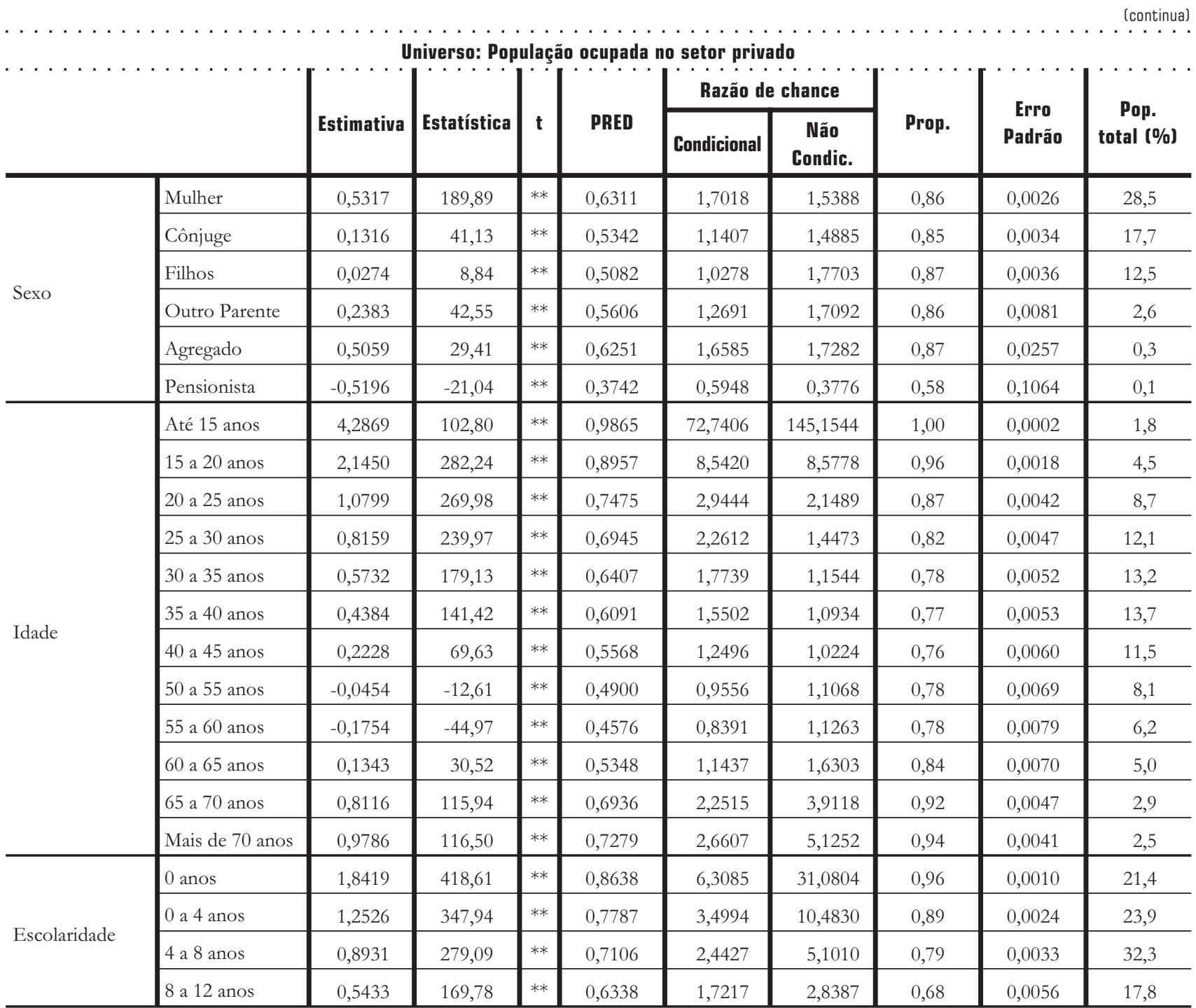


Modelo Logístico, análise dos parâmetros estimados 1993 compatível década 80 - Não Contribui para a Previdência - Conta-Própria

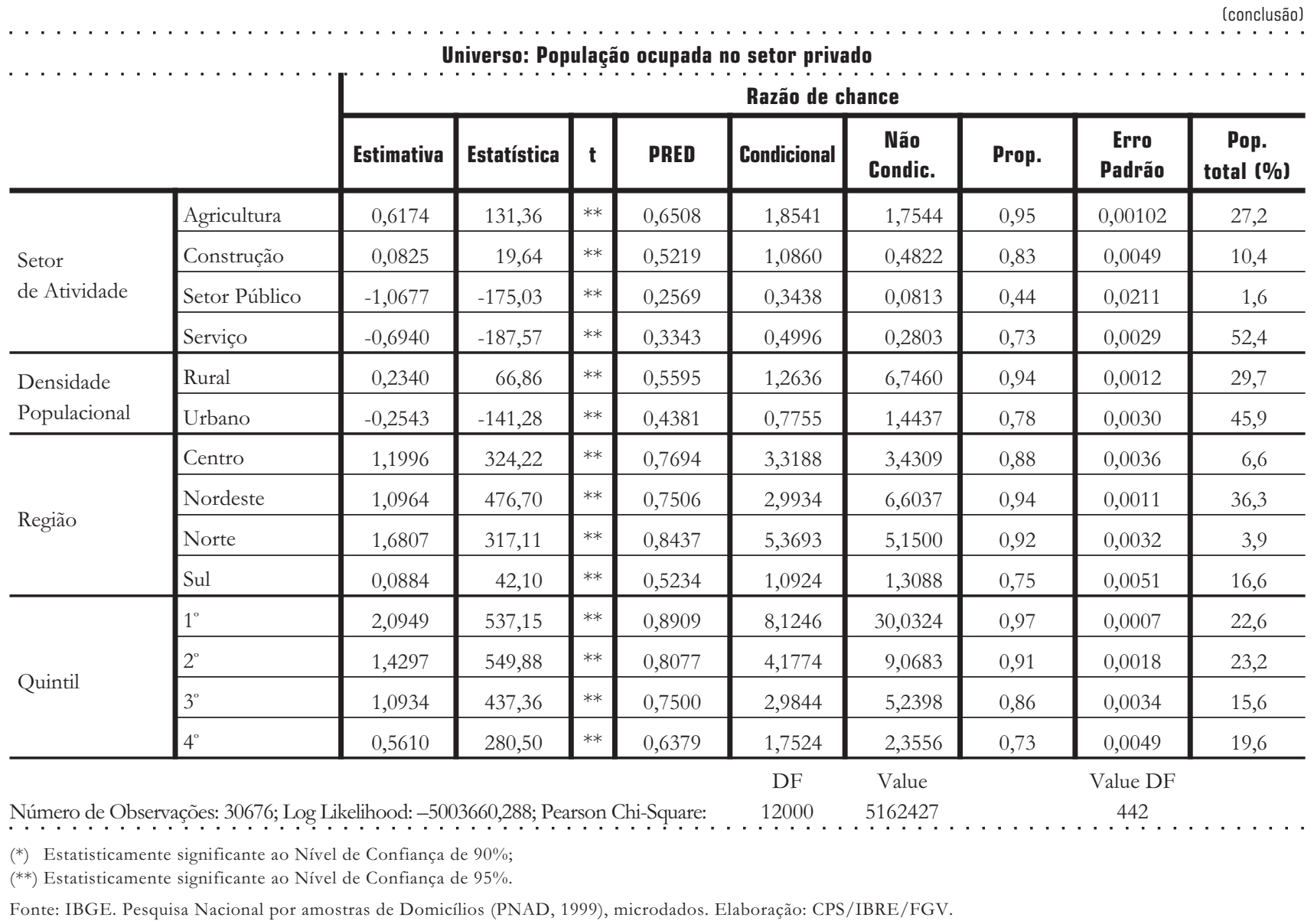

Obs: Variáveis omitidas em ordem: homem, chefe de Família, idade entre 45 e 50 anos, mais de 12 anos de estudo completos, setor industrial, metropolitano, região sudeste, $5^{\circ}$ quintil.

\begin{tabular}{l|c|c}
\multicolumn{2}{c}{$\mathbf{N}^{0}$ de Pessoas } & $\%$ \\
\hline Não Contribui & 11.699 .359 & 81,1 \\
\hline Contribui . . . . . 2.727.650 . . . . . . . .
\end{tabular}


Modelo Logístico, análise dos parâmetros estimados 1996 compatível década 80 - Não Contribui para a Previdência - Conta-Própria

(continua)

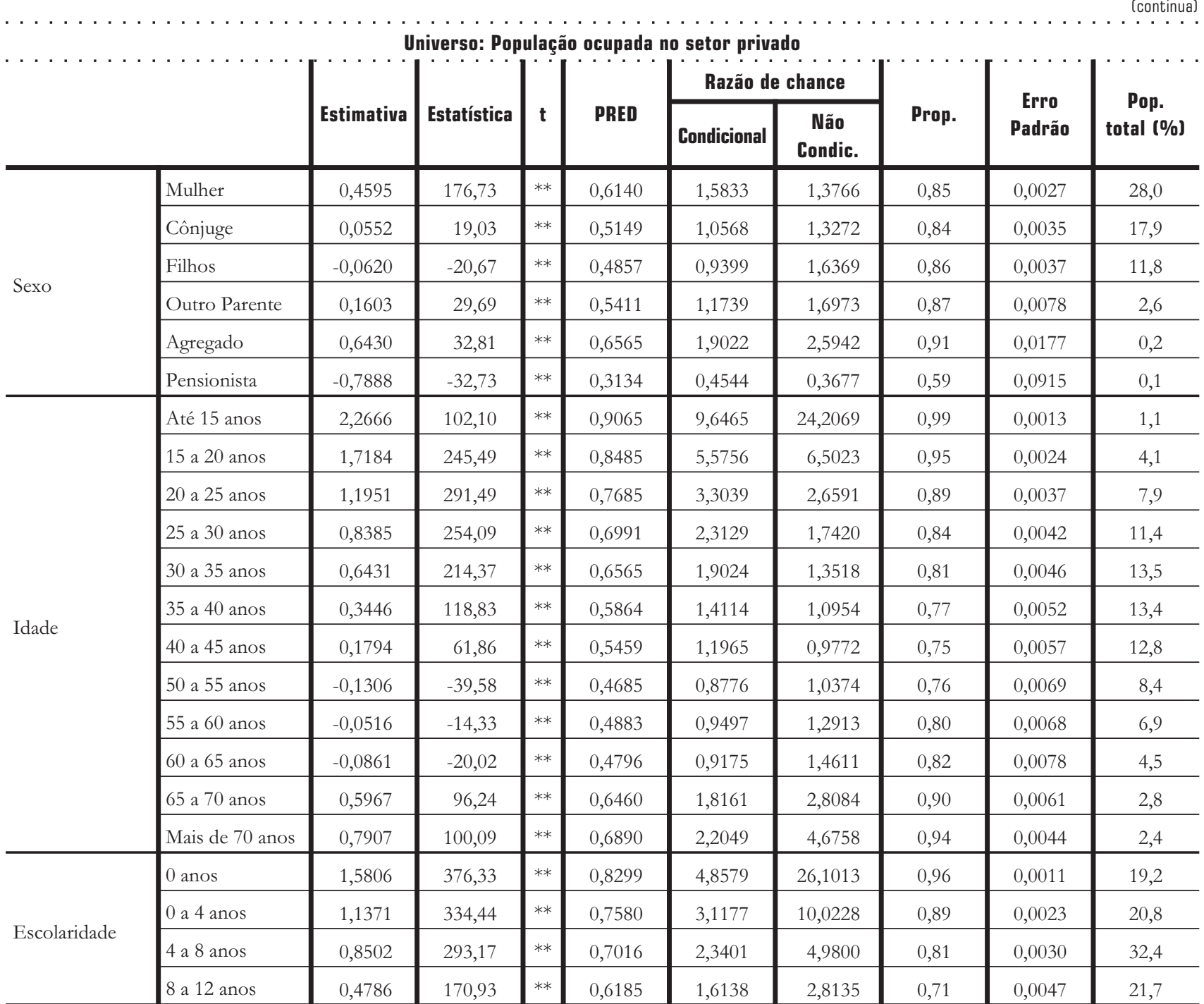


Modelo Logístico, análise dos parâmetros estimados 1996 compatível década de 80 - Não Contribui para a Previdência - Conta-Própria

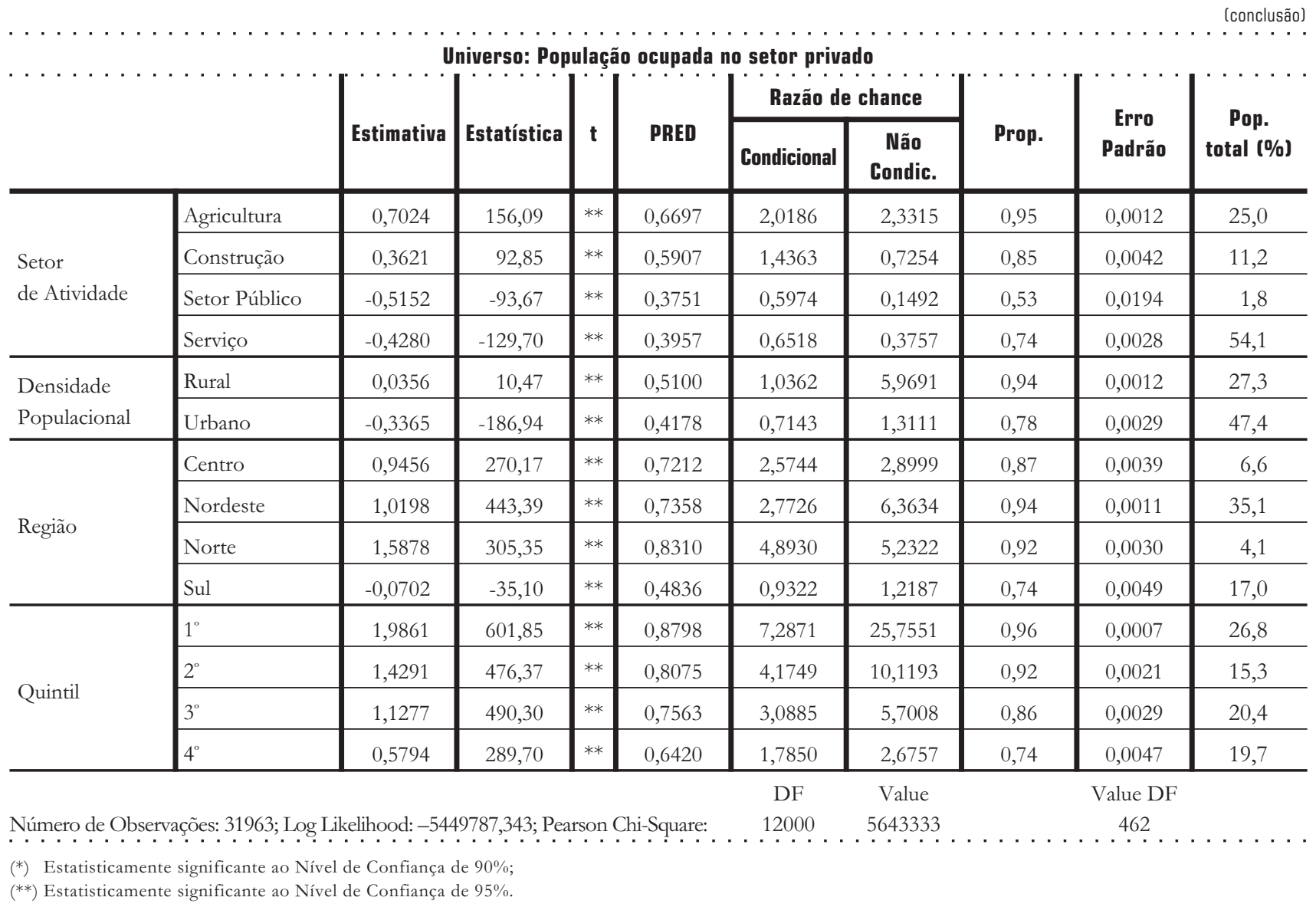

Fonte: IBGE. Pesquisa Nacional por amostras de Domicílios (PNAD, 1999), microdados. Elaboração: CPS/IBRE/FGV.

Obs: Variáveis omitidas em ordem: homem, chefe de Família, idade entre 45 e 50 anos, mais de 12 anos de estudo completos, setor industrial, metropolitano, região sudeste, $5^{\circ}$ quintil.

\begin{tabular}{l|c|c}
\multicolumn{2}{c}{$\mathbf{N}^{0}$ de Pessoas } & $\%$ \\
\hline Não Contribui & 12.316 .076 & 81,2 \\
\hline Contribui _. . . . & 2.856 .026 & $18,8 \ldots$ \\
\hline
\end{tabular}


Modelo Logístico, análise dos parâmetros estimados 1999 compatível década 80 - Não Contribui para a Previdência - Conta-Própria

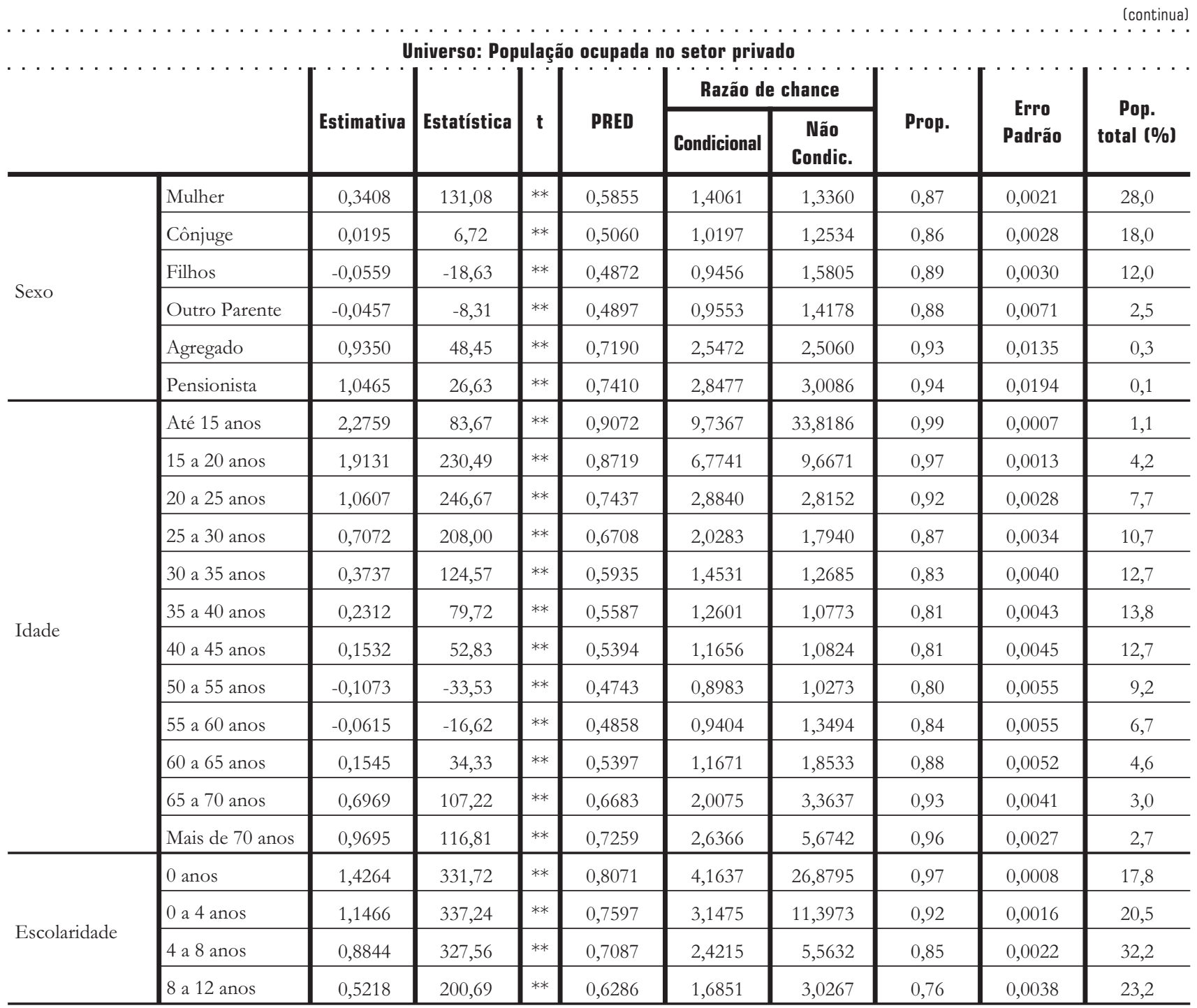


Modelo Logístico, análise dos parâmetros estimados 1999 compatível década 80 - Não Contribui para a Previdência - Conta-Própria

(conclusão)

Universo: População ocupada no setor privado

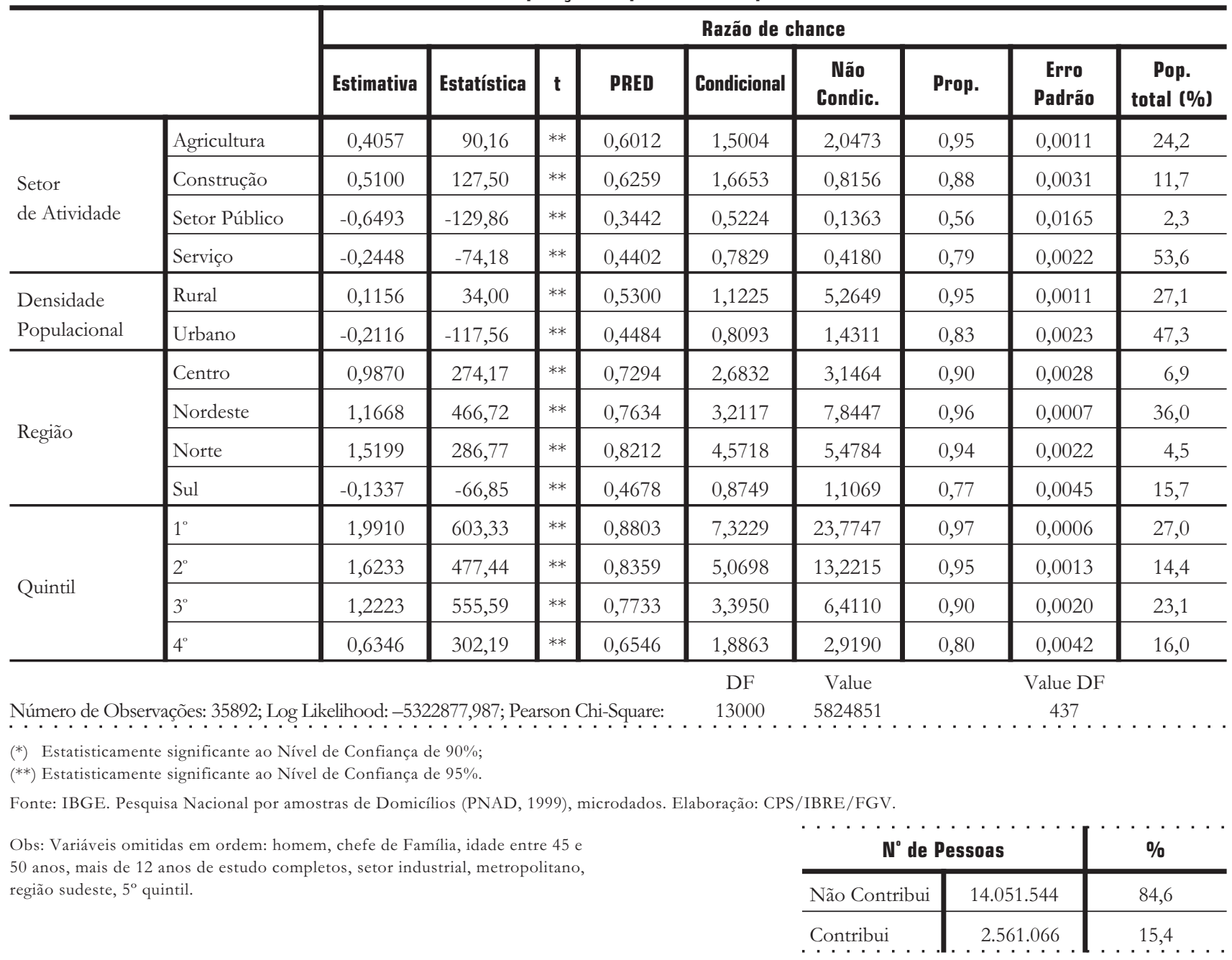

